\title{
Optimization of Ventilation Energy Demands and Indoor Air Quality in the ZEBRAlliance Homes
}

September 2013

\author{
Prepared by \\ Diana E. Hun \\ Mark C. Jackson \\ Som S. Shrestha
}




\section{DOCUMENT AVAILABILITY}

Reports produced after January 1, 1996, are generally available free via the U.S. Department of Energy (DOE) Information Bridge.

Web site http://www.osti.gov/bridge

Reports produced before January 1, 1996, may be purchased by members of the public from the following source.

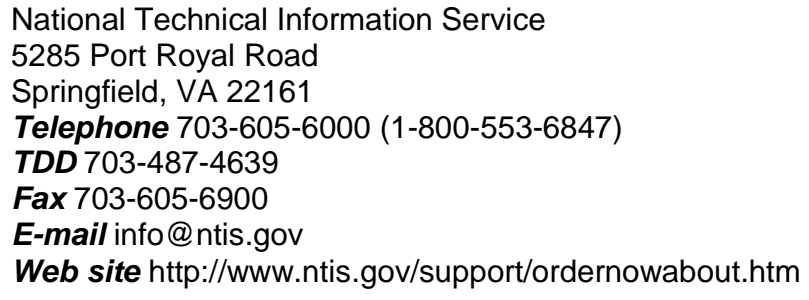

Reports are available to DOE employees, DOE contractors, Energy Technology Data Exchange (ETDE) representatives, and International Nuclear Information System (INIS) representatives from the following source.

Office of Scientific and Technical Information

P.O. Box 62

Oak Ridge, TN 37831

Telephone 865-576-8401

Fax 865-576-5728

E-mail reports@osti.gov

Web site http://www.osti.gov/contact.html

This report was prepared as an account of work sponsored by an agency of the United States Government. Neither the United States Government nor any agency thereof, nor any of their employees, makes any warranty, express or implied, or assumes any legal liability or responsibility for the accuracy, completeness, or usefulness of any information, apparatus, product, or process disclosed, or represents that its use would not infringe privately owned rights. Reference herein to any specific commercial product, process, or service by trade name, trademark, manufacturer, or otherwise, does not necessarily constitute or imply its endorsement, recommendation, or favoring by the United States Government or any agency thereof. The views and opinions of authors expressed herein do not necessarily state or reflect those of the United States Government or any agency thereof. 


\title{
Optimization of Ventilation Energy Demands and Indoor Air Quality in the ZEBRAlliance Homes
}

\author{
Diana E. Hun \\ Mark C. Jackson \\ Som S. Shrestha
}

Date Published: September 2013

Prepared by

OAK RIDGE NATIONAL LABORATORY

Oak Ridge, Tennessee 37831-6283

managed by

UT-BATTELLE, LLC

for the

U.S. DEPARTMENT OF ENERGY

under contract DE-AC05-00OR22725 


\section{Content}

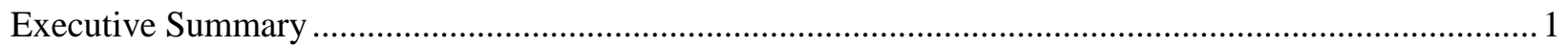

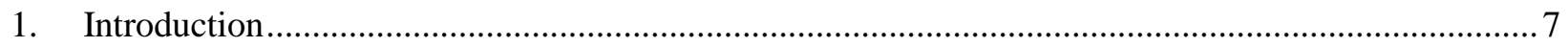

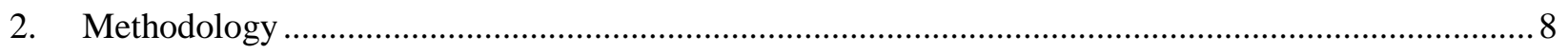

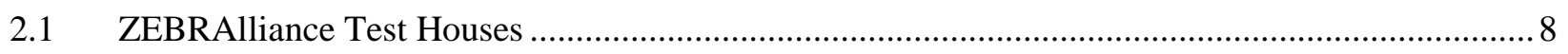

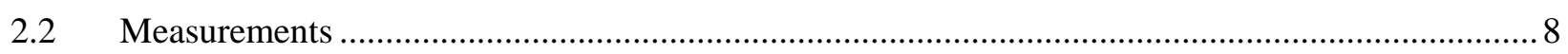

2.2.1 Volatile Organic Compounds and Formaldehyde ….......................................................... 8

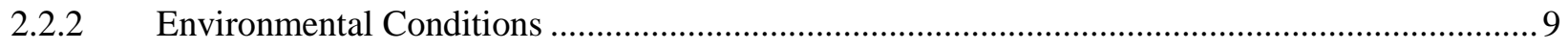

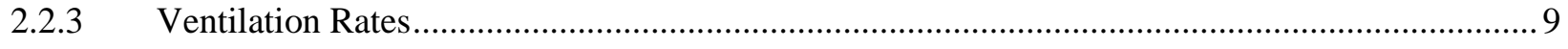

2.3 Techniques to Reduce Formaldehyde Concentrations ............................................................ 10

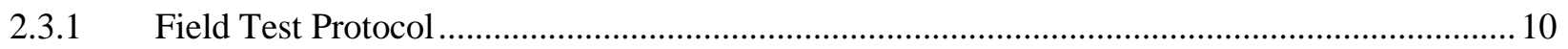

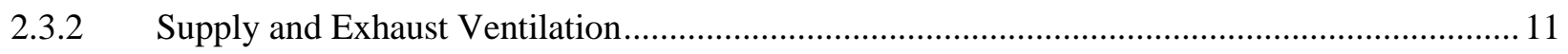

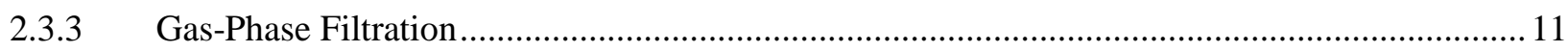

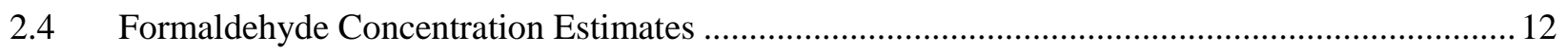

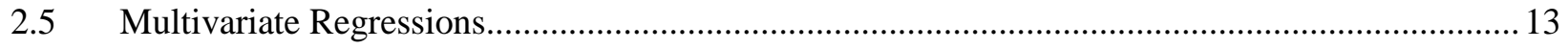

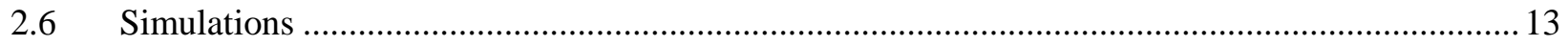

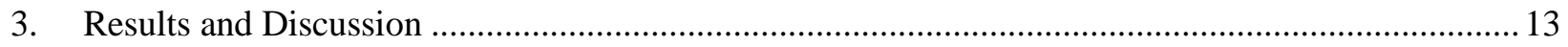

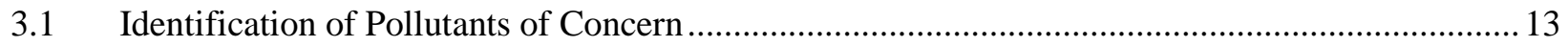

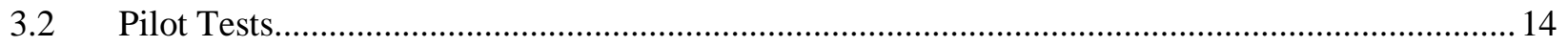

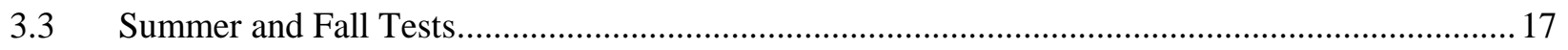

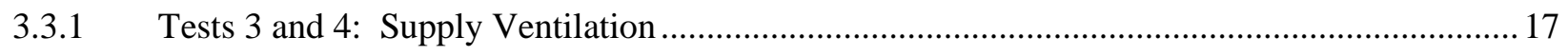

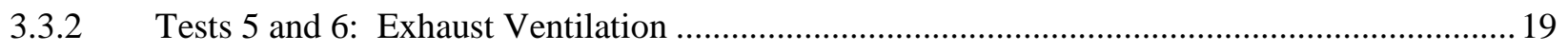

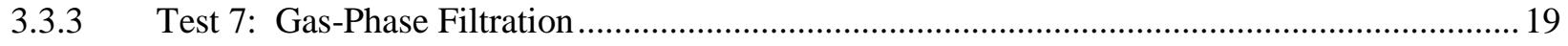

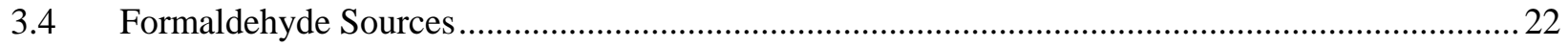

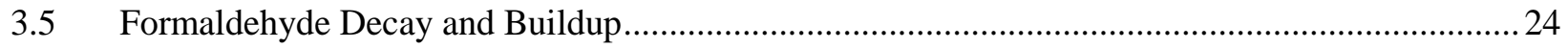

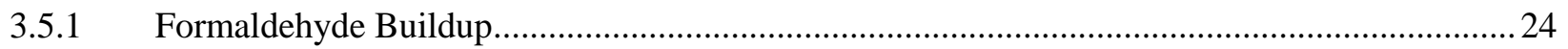

3.5.2 Formaldehyde Decay due to Supply Ventilation .................................................................25

3.5.3 Formaldehyde Decay due to Gas-Phase Filtration.................................................................26

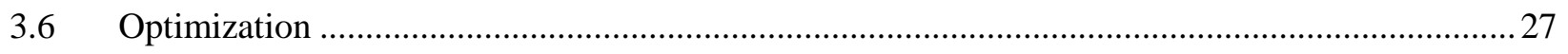

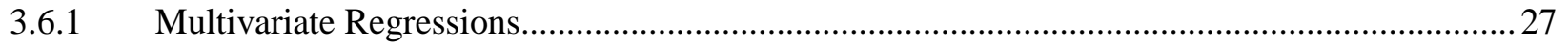

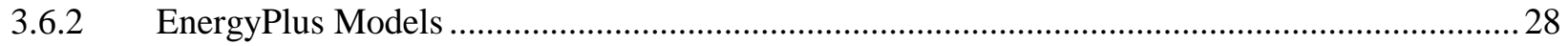

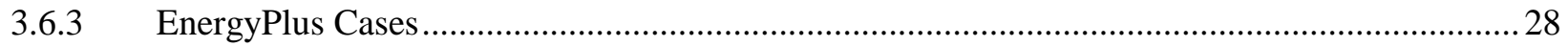




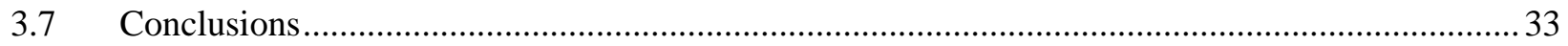

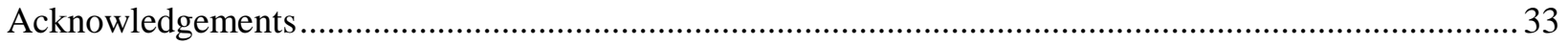

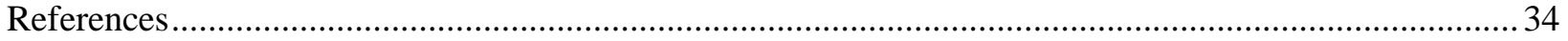

Appendix A: Description of the ZEBRAlliance Houses........................................................................... 37

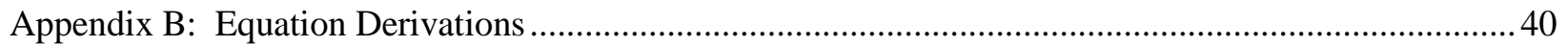

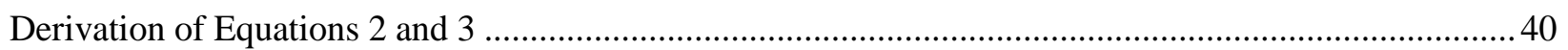

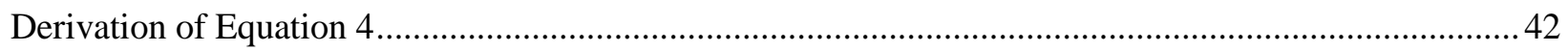

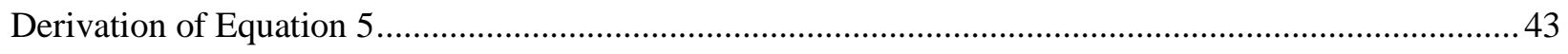

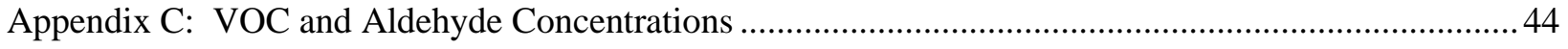

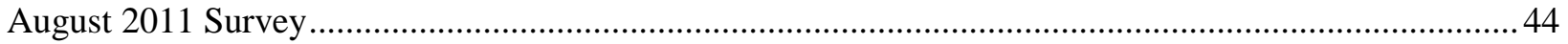

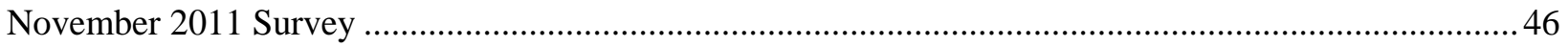




\section{List of Figures}

Figure 1. Mechanical ventilation and gas-phase filtration setup.......................................................... 11

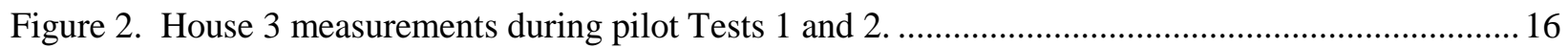

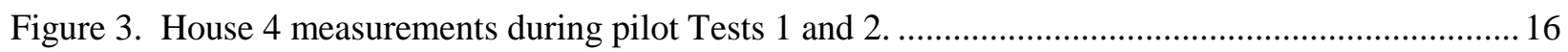

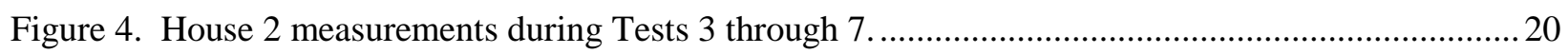

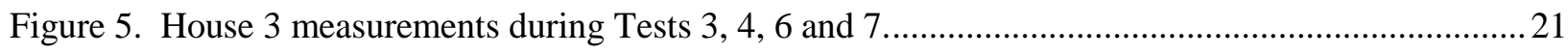

Figure 6. Seasonal formaldehyde concentrations (DNPH) from the four test houses. ............................22

Figure 7. Formaldehyde concentrations (DNPH) collected in March and July 2012 from various locations

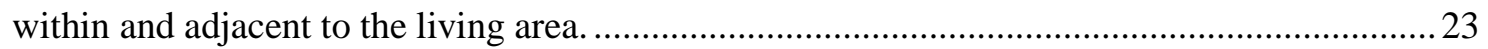

Figure 8. Measured and estimated 24-hour average formaldehyde concentrations from multivariate

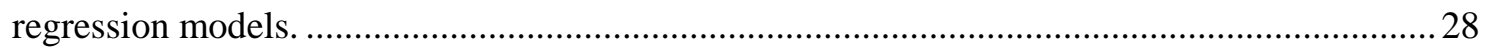

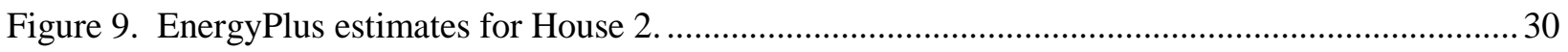

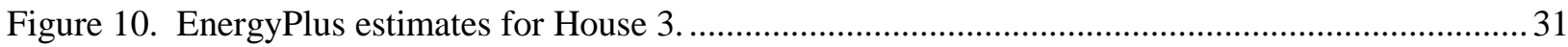




\section{List of Tables}

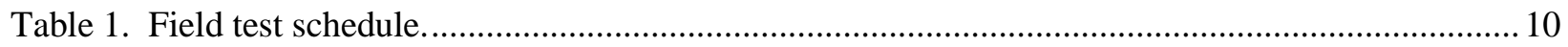

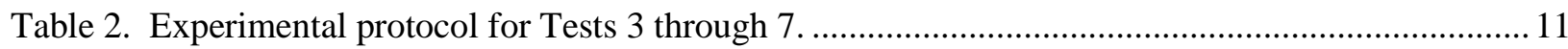

Table 3. Formaldehyde concentrations and environmental conditions during pilot tests Tests 1 and 2 in

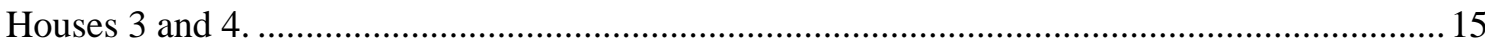

Table 4. Formaldehyde concentrations and environmental conditions during Tests 3 through 7 in Houses

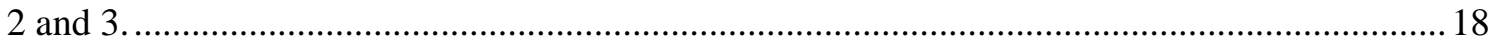

Table 5. Ventilation rates, time constants $(K L)$ of storage materials, filtration system removal rate constants $\left(\eta Q_{f} / V\right)$, and time to reach $95 \%$ and $105 \%$ of steady-state concentrations.

Table 6. Cases simulated with EnergyPlus. 


\section{Executive Summary}

High-performance homes require that ventilation energy demands and indoor air quality (IAQ) be simultaneously optimized. Researchers have primarily addressed these two areas independently because of the assumption that their goals have to be mutually exclusive. This assumption is based on the fact that the typical mechanism to reduce the concentration of indoor air pollutants has been dilution through increased ventilation, which causes heating, ventilation and air conditioning (HVAC) units to consume more energy. High-performance homes aim to provide the essential energy end-uses (for example, water heating, refrigeration, space heating, and air conditioning) in an energy efficient manner. Given that IAQ is among these essential energy end-uses, we investigated means to optimize the concentration of indoor air pollutants and ventilation energy demands. To this end, we conducted tests in four houses located in Oak Ridge, TN, that were 11 to 20 months old, energy efficient (i.e., expected to consume 50\% less energy than a house built per the 2006 International Residential Code), airtight (i.e., natural ventilation rate $\sim 0.02$ to $0.2 \mathrm{~h}^{-1}$ ), unoccupied, and unfurnished. Our evaluation consisted of identifying air pollutants of concern in these homes that could generally serve as indicators of IAQ, and conducting field experiments and computer simulations to determine the effectiveness and energy required by various techniques that lessened the concentration of these contaminants.

We selected formaldehyde as the main pollutant of concern based on initial air sampling surveys. Indoor formaldehyde concentrations $\left(C_{i n}\right)$ were somewhat similar in Houses 1, 2 and 4, ranging from $22 \mathrm{ppb}$ in the winter to $103 \mathrm{ppb}$ in the summer. Concentrations in House 3 were greater and varied between $65 \mathrm{ppb}$ during the cooler months and $173 \mathrm{ppb}$ during the warmer season. Higher summer $C_{\text {in }}$ values were encountered primarily because emission rates from sources rise with increases in temperature, and to a lesser extent because natural ventilation decreases with lower indoor to outdoor temperature differentials. Elevated concentrations in House 3 were probably due to wall materials given that air samples from the cavities of exterior walls were the highest found in this study, ranging from 239 to $324 \mathrm{ppb}$ during a summer survey. In House 3 , the exterior double walls were framed with $2 \times 4$ laminated strand lumber (LSL) studs at 24 " on center, interior single walls were framed with $2 \times 4$ LSL studs at 16 " on center, and top and bottom plates were also made of $2 \times 4$ LSL members. Although we did not measure formaldehyde emission rates from LSL samples, similar pressed-wood products have been identified as long-term sources of formaldehyde (Kelly et al. 1999; Hodgson et al. 2002). In contrast, the other test homes were framed with regular sawn lumber.

Formaldehyde levels in all of the test houses were somewhat higher than what Offermann (2009) observed in a recent study of California homes $\left(50^{\text {th }} \mathrm{ptile}=29 \mathrm{ppb}, 95^{\text {th }} \mathrm{ptile}=77 \mathrm{ppb}\right)$. Potential reasons behind this discrepancy include that the research houses had been minimally ventilated due to airtight construction and mechanical ventilation set to $30 \mathrm{cfm}$ (Houses 1 and $2=$ $0.04 \mathrm{~h}^{-1}$, Houses 3 and $4=0.06 \mathrm{~h}^{-1}$ ) by the initial researchers since their completion, which slowed the decline in emission rates from formaldehyde sources. In contrast, the ventilation rates in the California homes were higher: $50^{\text {th }}$ ptile $=0.26 \mathrm{~h}^{-1}, 95^{\text {th }} \mathrm{ptile}=1.4 \mathrm{~h}^{-1}$. Additionally, the California homes were two to four years old, so sources had been aging for a longer period of time than in the research houses. Lastly, formaldehyde emission rates in the test houses could have also been higher because most of the data were collected in the summer, while the California homes were monitored during the summer and winter. We installed an energy 
recovery ventilator (ERV) in House 3 to lower formaldehyde concentrations through increased mechanical ventilation and minimal energy penalties.

Through field tests we evaluated the effect of supply and exhaust ventilation, and an off-the-shelf gas-phase filtration system on indoor formaldehyde concentrations. Results suggest that exhaust ventilation is not as effective in decreasing $C_{\text {in }}$ as supply ventilation probably because the former induces airflows that transport pollutants within the cavities of exterior walls into the living area, which would make dilution of indoor contaminants with fresh air less effective. More research is needed to evaluate the effectiveness of exhaust ventilation given that, among the various types of residential mechanical ventilation systems, exhaust ventilation is likely the most popular because it can be attained economically with bathroom fans.

Field experiments also indicated that the tested gas-phase filtration system, which consisted of activated coconut shell carbon with a proprietary additive, was successful in reducing $C_{i n}$. Using the whole-house concentrations that were measured while formaldehyde was decreasing due to filtration, we calculated a filter removal efficiency $(\eta)$ of 0.21 in four tests. We also estimated the single-pass removal efficiency by sampling the air upstream and downstream of the filtration system on one occasion; $\eta$ in this case was 0.85 . The reason why the single-pass efficiency method yielded a filter removal efficiency that was four times higher than what was obtained through the whole-house method may be explained by the fact that the latter method included the interactions that formaldehyde experiences in a realistic setting (e.g., continuous variations in emission rates due to changes in temperature and ventilation, and sorption to building materials) while the former method did not.

We also utilized the field data to examine the role of sorption kinetics during and after efforts to reduce formaldehyde concentrations through higher ventilation and filtration. More specifically, we tried to determine if the rate at which $C_{i n}$ decreases or decays with higher ventilation or gasphase filtration could be expedited by the adsorption of formaldehyde to building materials. Similarly, we investigated the possibility that sorption kinetics could slow the rate at which air contaminants increase or buildup after higher ventilation or filtration are reduced or discontinued. Expediting the decay and/or slowing the buildup of pollutants could help reduce ventilation energy demands and exposure to air contaminants.

The equations we derived indicate that the rate at which decay and buildup occur are significantly dependent on: ventilation rate, source time constant $(K L)$ of storage materials, and filtration system removal rate constant $\left(\eta Q_{f} / V\right)$; the larger these factors are, the faster the decay and buildup. Here, storage materials are those that are not inherent sources of formaldehyde, but become secondary sources as this pollutant adsorbs and desorbs from them. In the research homes, ventilation (natural plus mechanical per ASHRAE 62.2) ranged between 0.22 to $0.33 \mathrm{~h}^{-1}$. Using the field data, we estimated the source time constant of storage materials to be in the order of $0.15 \mathrm{~h}^{-1}$ in House 2 and $0.18 \mathrm{~h}^{-1}$ in Houses 3 and 4 , and the filtration system removal rate constant to be $0.21 \mathrm{~h}^{-1}$ in House 2 and $0.34 \mathrm{~h}^{-1}$ in Houses 3 and 4 . These values suggest that $K L$ can be comparable in magnitude to the ventilation rate in airtight homes; consequently, the effects from sorption kinetics have to be taken into consideration when assessing the speed of decay or buildup of $C_{i n}$ in homes with tight construction. Neglecting this effect can lead to the incorrect assumption that formaldehyde buildup to steady-state would take days in an airtight 
home, while in fact sorption kinetics can expedite this process to hours. This information is of relevance when examining exposures to formaldehyde during energy conservation strategies, such as intermittent ventilation with on/off cycles that last several hours, where the rate at which formaldehyde concentrations increase can significantly affect occupant exposure.

We developed models for Houses 2 and 3 to predict 24-hr average formaldehyde concentrations. To this end, we conducted multivariate regressions using field data to evaluate the effect of indoor and outdoor temperature $\left(T_{i n}, T_{\text {out }}\right)$, indoor relative humidity $\left(R H_{\text {in }}\right)$, and ventilation rate on $C_{i n}$. Regressions suggest a strong dependency of formaldehyde concentrations on indoor temperature and ventilation: a $0.56^{\circ} \mathrm{C}\left(1^{\circ} \mathrm{F}\right)$ change in $T_{\text {in }}$ could lead to variations in $C_{\text {in }}$ of 5.2 ppb and $18 \mathrm{ppb}$ in Houses 2 and 3, respectively; similarly, changes in ventilation of $0.05 \mathrm{~h}^{-1}$ (House $2=38 \mathrm{cfm}$, House $3=24 \mathrm{cfm}$ ) could cause $C_{\text {in }}$ to vary by $4.5 \mathrm{ppb}$ in House 2 and $14 \mathrm{ppb}$ in House 3. Although informative, these results should be used with caution because in their derivation we did not take into account source aging, which, over time, is expected to lower formaldehyde concentrations. Additionally, the field data that we used to generate the regression models were from unoccupied and unfurnished homes, and most of these data (82\% in House 2 and $73 \%$ in House 3) were collected during the summer.

We incorporated the regression equations for Houses 2 and 3 into EnergyPlus models to evaluate the cost-effectiveness of strategies that could be used to decrease formaldehyde concentrations. The four cases we explored are summarized in Table ES1. Case 1 served as the baseline scenario with ventilation rates per ASHRAE 62.2 and thermostat setpoints per the Building America protocol; Case 2 decreased the cooling setpoint by $1.1^{\circ} \mathrm{C}\left(2^{\circ} \mathrm{F}\right)$ during the cooling season; Case 3 increased the ASHRAE mechanical ventilation rate by a factor of two; and Case 4 employed gas-phase filtration and decreased the ASHRAE ventilation by half. Also, in all the simulations we used the 2012 weather data that we collected at the test site, and we assumed the electricity cost to be $\$ 0.10 / \mathrm{KWh}$. Results from the baseline case suggest that summer concentrations exceeded winter values by a factor of two in House 2 (July $=51 \mathrm{ppb}$, January $=$ $24 \mathrm{ppb}$ ) and a factor of four in House 3 (July $=168 \mathrm{ppb}$, January $=38 \mathrm{ppb}$ ). Consequently, efforts to decrease exposure to formaldehyde would be of more consequence from May to September. During these months, Cases 2, 3 and 4 yielded similar results as shown in Figures ES1 and ES2: $C_{\text {in }}$ decreased by about $20 \%$ in both homes, while causing energy cost penalties that ranged from $\sim \$ 5$ to $\sim \$ 15 /$ month depending on the outdoor temperatures. Note that these estimates are highly influenced by the fact that the test houses are airtight, well insulated, have very efficient HVAC units, and are located in a mixed-humid climate. 
Table ES1. Cases simulated with EnergyPlus.

\begin{tabular}{|c|c|c|c|}
\hline Case & Mechanical Ventilation $\left(\mathrm{cfm}, \mathrm{h}^{-1}\right)$ & Indoor Temperature $\left({ }^{\circ} \mathrm{C},{ }^{\circ} \mathrm{F}\right)$ & Gas-Phase Filtration \\
\hline 1 & ASHRAE 62.2: & Building America protocol: & \\
\hline \multirow[t]{2}{*}{ (Baseline) } & House $2=75,0.1$ & Heating setpoint $=21.7,71$ & - \\
\hline & House $3=60,0.13$ & Cooling setpoint $=24.4,76$ & \\
\hline \multirow[t]{3}{*}{2} & ASHRAE 62.2: & Heating setpoint $=21.7,71$ & \\
\hline & House $2=75,0.1$ & Cooling setpoint $=\underline{23.3,74}$ & - \\
\hline & House $3=60,0.13$ & & \\
\hline \multirow[t]{3}{*}{3} & $\underline{\mathbf{2}} \times$ ASHRAE 62.2 & Building America protocol: & \\
\hline & House $2=\underline{150,0.2}$ & Heating setpoint $=21.7,71$ & - \\
\hline & House $3=\underline{120,0.26}$ & Cooling setpoint $=24.4,76$ & \\
\hline \multirow[t]{3}{*}{4} & $\underline{0.5} \times$ ASHRAE 62.2 : & Building America protocol: & House 2: $\eta Q_{f} / V=0.11 \mathrm{~h}^{-1}$ \\
\hline & House $2=\underline{38,0.05}$ & Heating setpoint $=21.7,71$ & House 3: $\eta Q_{f} / V=0.17 \mathrm{~h}^{-1}$ \\
\hline & House $3=\underline{30,0.07}$ & Cooling setpoint $=24.4,76$ & \\
\hline
\end{tabular}

Each of the investigated strategies poses advantages and disadvantages. The first strategy, lowering the cooling setpoint, produces no capital cost, focuses on the months when formaldehyde emissions are the highest, and lowers $R H_{\text {in }}$ during the summer when these tend to be the highest. A major drawback of this strategy is that it would increase energy demand during the time of day when utilities experience their peak loads. The second strategy, increasing mechanical ventilation rates, reduces contaminant concentrations due to emissions from longterm sources of pollutants. This strategy will not require significant additional capital cost in airtight homes other than installing a larger outdoor air intake duct than what is required to meet ASHRAE's minimum ventilation rates. Disadvantages from higher mechanical ventilation include that it will increase latent loads in the summer, which could be difficult to manage by HVAC units without a dedicated dehumidification system. Furthermore, energy penalties during the winter are significantly higher, but it could be argued that increased mechanical ventilation is not needed during the heating season because of lower indoor concentrations and greater infiltration. The third strategy, gas-phase filtration and reduced mechanical ventilation, lessens both formaldehyde and VOC concentrations. Moreover, lower ventilation rates reduce indoor concentrations of pollutants that are generated outdoors, and decreases latent loads during the summer given that outdoor sources are dominant during this period. However, the filtration system has an initial capital cost of $\sim \$ 2800$, the price to replace the carbon canister is on the order of $\$ 625$ per year, and the system consumes $200 \mathrm{~W}$ or about $\$ 180$ per year. 

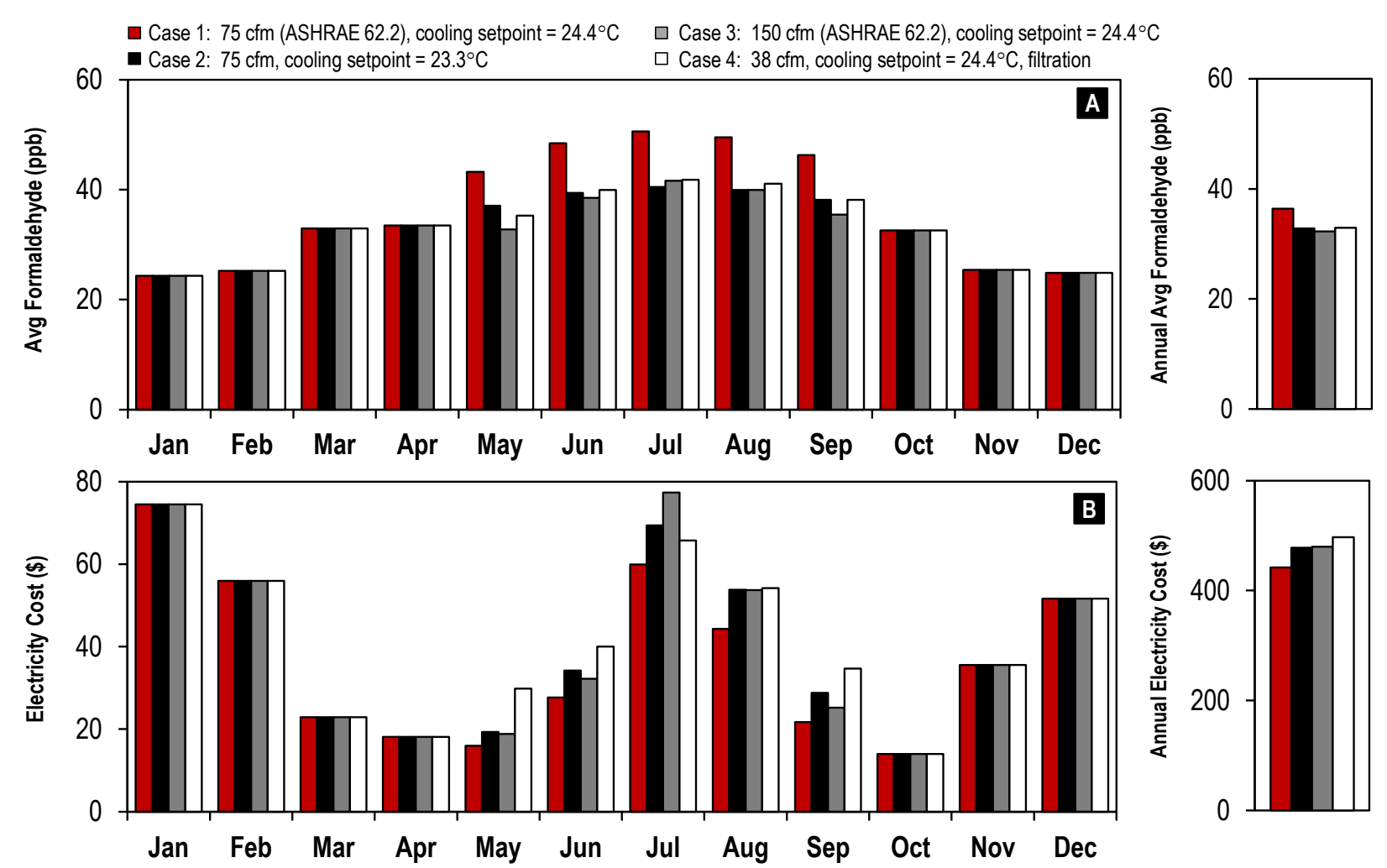

Figure ES1. Optimized formaldehyde concentrations and electricity costs due to HVAC and filtration systems in House 2. 

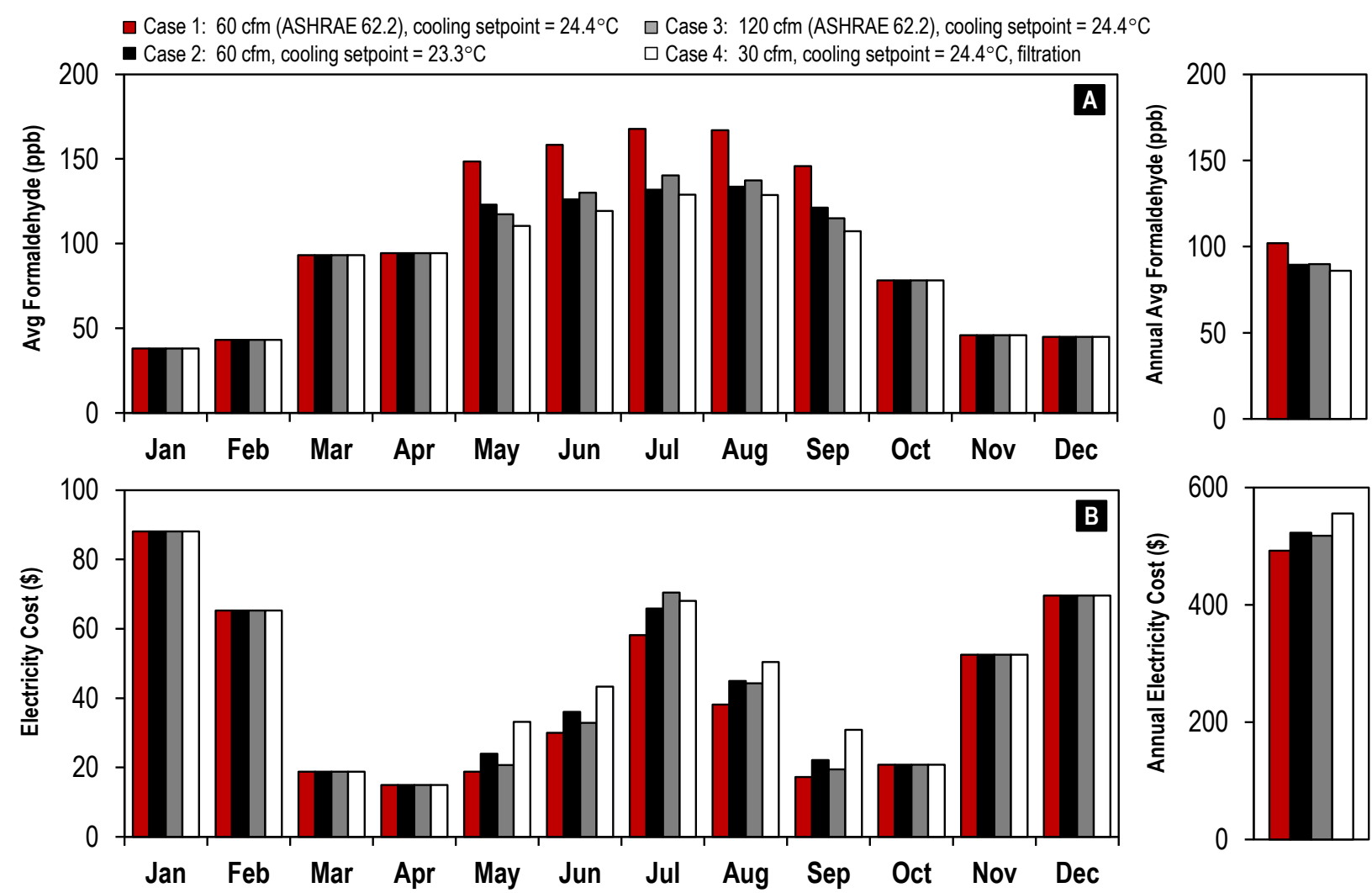

Figure ES2. Optimized formaldehyde concentrations and electricity costs due to HVAC and filtration systems in House 3.

The aforementioned results suggest that an approximate $20 \%$ reduction in formaldehyde concentrations can be achieved from May to September in high-performance homes (i.e., airtight, good insulation and efficient HVAC unit(s)). This reduction can be attained through minimal capital investment and low to moderate increases in electricity costs depending on the climate zone where the house is located. Additionally, given that emission rates from various sources of pollutants, such as formaldehyde, are likely to be lower in the winter, it may be possible to propose decreasing minimum ASHRAE mechanical ventilation rates during these months, but this is contingent upon reaching a consensus on acceptable contaminant levels in homes. These suggestions could lead to significant energy savings because winter ventilation energy demands are usually higher than those from other seasons throughout most of the country. The evaluated strategies could be optimized further by taking into account setback temperatures and/or setback mechanical ventilation rates in conjunction with occupancy-based schedules to decrease both energy use and exposure to air contaminants. 


\section{Introduction}

Healthy and efficient homes require both lower ventilation energy demands and adequate indoor air quality (IAQ). Decreasing uncontrolled ventilation in residences is necessary because infiltration and exfiltration are responsible for about 16 to $50 \%$ of air conditioning loads (Huang et al. 1999; Sherman and Matson 1997). Researchers have indicated that strict airtightness requirements set by the IECC 2012 can be met in new construction and deep retrofit houses (Boudreaux et al. 2012; Offermann 2009; Miller et al. 2010). Although it consumes energy, mechanical ventilation is essential in airtight residences to reduce human exposure to air pollutants because on average Americans spend approximately $70 \%$ of their time in their homes (Klepeis et al. 2001), and sources of pollutants in homes can significantly influence exposure to air contaminants (Adgate et al. 2004; Clayton et al. 1999; Hun et al. 2009; Wallace et al. 1987).

Even though lower ventilation energy demands and adequate IAQ are necessary in healthy and energy efficient homes, minimal research is available on how to reach an acceptable balance between these opposing requirements. Mortensen et al. (2011), Sherman et al. (2011), and Sherman and Walker (2011) have pioneered the optimization of intermittent ventilation to both reduce energy consumption and to yield exposures to indoor pollutants that are equivalent to those generated through ASHRAE Standard 62.2 continuous ventilation rates. Although this work indicated promising results, most of it is based on simulations and assumptions on indoor pollutant concentrations. Furthermore, the basis of their work, ASHRAE 62.2, specifies minimum ventilation rates that do not address human exposure to air pollutants of concern; instead, these are grounded on occupant dissatisfaction with odors and sensory irritation.

The present research aimed to enhance the aforementioned work on ventilation by integrating into the optimization process actual indoor pollutant concentrations, as well as active and passive techniques that have been studied in the IAQ realm, but their potential to concurrently reduce residential energy consumption has yet to be explored. Researchers have evaluated the effectiveness of air cleaning technologies on the removal of volatile organic compounds (VanOsdell et al. 1996; Zhang et al. 2003), formaldehyde (Sidheswaran et al. 2011), and particles (Fisk et al. 2002; Waring et al. 2008). We used gaseous air cleaners to simultaneously reduce pollutant concentrations and ventilation rates given their potential to decrease energy use. Additionally, we examined if this active technique could be supplemented by sorption kinetics. More specifically, we tried to determine if the rate at which pollutant concentrations decay with higher ventilation or gas-phase filtration could be expedited by the adsorption or desorption of these contaminants to building materials. Similarly, we investigated the possibility that sorption kinetics could slow the rate at which air contaminants buildup after higher ventilation or filtration are reduced or discontinued. Expediting the decay and/or slowing the buildup of pollutants could help reduce ventilation energy demands and exposure to air contaminants.

The objectives of this study were to:

1. Identify air pollutant(s) of concern, and their potential sources, that could be used as surrogates of IAQ in new houses;

2. Estimate the effectiveness of gas-phase filtration systems to decrease the concentration of the identified pollutant(s);

3. Evaluate the adsorption/desorption kinetics of the pollutant(s) of concern; 
4. Optimize ventilation energy demands and IAQ through ventilation, gas-phase filtration, source identification, and sorption kinetics; and

5. Compare exposures to air pollutant(s) from the proposed tests to those obtained through the ventilation recommendations in ASHRAE Standard 62.2-2010.

To attain these goals, we conducted seasonal evaluations at the ZEBRAlliance houses. These test homes were new, unoccupied, unfurnished and airtight (natural ventilation rate $\sim 0.02$ to 0.2 $\mathrm{h}^{-1}$ ). Moreover, these buildings were instrumented to collect data on indoor and outdoor environmental conditions, simulate occupancy, and measure energy use from household activities. We focused our efforts on two of the four residences, although we occasionally gathered IAQ data from all houses. Air sampled in August and November 2011 was analyzed for volatile organic compounds (VOCs) and aldehydes typically found in residences. Results identified formaldehyde as the main pollutant of concern in these residences; consequently, subsequent experiments focused on reducing indoor formaldehyde concentrations, although the evaluated strategies will likely be effective at lessening VOC concentrations as well.

\section{Methodology}

\subsection{ZEBRAlliance Test Houses}

The Zero Energy Building Research Alliance (ZEBRA) is a federal and private-sector consortium that collaborated in the construction and evaluation of four homes in Oak Ridge, TN, that are expected to be at least 50\% more energy efficient than those that conform with the 2006 International Residential Code (IRC). Consortium members include Schaad Companies LLC, the Tennessee Valley Authority (TVA), Oak Ridge National Laboratory (ORNL), Barber McMurry Architects and the Department of Energy (DOE). The homes were designed as two pairs, where houses in each pair were built side-by-side and have the same floor plan (Appendix A; Table A1) to allow for the comparison of various technologies. Additionally, the houses were instrumented to simulate occupancy: showers, dishwasher, clothes washer and dryer, lights and heat sources are operated on a regular schedule. Construction of Houses 1 and 2 ended in January 2010, and of Houses 3 and 4 in September 2010.

The building envelope, HVAC systems and hot water heaters are the major differences among the houses. Miller et al. (2010) and Ally et al. (2011) describe the envelope systems and HVAC units that were utilized, respectively; this information is summarized in Appendix A.

\subsection{Measurements}

\subsubsection{Volatile Organic Compounds and Formaldehyde}

VOCs and formaldehyde were monitored with active sampling. VOCs were collected using Supelco thermal desorption tubes packed with Carbotrap. Formaldehyde was sampled with SKC 2,4-dinitrophenylhydrazine (DNPH) silica gel cartridges with potassium iodide ozone scrubbers. Air was drawn through the Supelco tubes and DNPH cartridges with sampling pumps; flow rates were measured at the beginning and end of a monitoring session with a rotameter during the pilot tests, and with a dry calibrator (Bios Defender 530) during the summer and fall tests. Most monitoring periods lasted close to 24 hours to capture diurnal effects and air was sampled at a 
rate of $\sim 200 \mathrm{cc} / \mathrm{min}$. Additionally, 1-hr and 2-hr air samples were collected at higher flow rates ( $500 \mathrm{cc} / \mathrm{min})$ to examine formaldehyde decay rates during tests (i.e., implementation of increased supply or exhaust ventilation, or gas-phase filtration), and formaldehyde buildup rates after tests. Analyses were performed at Matrix Analytical Laboratories, Inc. in Farmers Branch, TX, following a modified version of the Environmental Protection Agency (EPA) method EPA TO-11a for formaldehyde. Similarly, a modified version of EPA TO-17 was used for VOC analyses.

The relative uncertainty of the mass of formaldehyde collected in each DNPH cartridge and extracted with $5 \mathrm{ml}$ of acetonitrile was estimated following the procedure described by Willem et al. (2013). Results indicate that the relative uncertainty for formaldehyde was $11 \%$ at a $68 \%$ confidence level based on the contribution from trip blanks (5\%), duplicate samples (9.8\%), and air flow meter (1.2\%). The minimum detection limit (MDL) with a 95\% confidence of the 1-hr, 2-hr, and 24-hr samples are 7, 2, and $1 \mathrm{ppb}$, respectively.

Air samples were collected simultaneously indoors and outdoors. Indoor monitoring was conducted in the main living area on the first floor, or at other locations that could be acting as main sources of pollutants (e.g., garage, crawlspace). Outdoor measurements were collected from the covered front porch of one of the houses.

Real-time formaldehyde measurements were also gathered every 30 minutes with Shinyei colorimetric monitors to improve the resolution on the effects from increased ventilation, gasphase filtration, and diurnal cycles on indoor concentrations.

\subsubsection{Environmental Conditions}

Indoor temperature and relative humidity were monitored with Honeywell 192-103LET-A01 and Honeywell HIH-4000 sensors, respectively. Outdoor temperature and relative humidity measurements were gathered with a Campbell Scientific CS215 sensor. Indoor data were reported every 15 minutes, while outdoor parameters were recorded every minute.

\subsubsection{Ventilation Rates}

Ventilation or air exchange rates (AER) were estimated with the tracer gas decay method. Realtime data were sampled and analyzed with an Innova 1303 multipoint sampler/doser and an Innova 1412 photoacoustic gas analyzer, respectively. The tracer gases used were 1,1,1,2tetrafluoroethane $\left(\mathrm{C}_{2} \mathrm{H}_{2} \mathrm{~F}_{4}\right.$, also known as the freon $\left.\mathrm{R} 134 \mathrm{a}\right)$, and sulfur hexafluoride $\left(\mathrm{SF}_{6}\right)$ to a lesser extent; their respective detection limits at $20^{\circ} \mathrm{C}$ are 11 and $10 \mathrm{ppb}$. In addition to R134a and $\mathrm{SF}_{6}$, the analyzer also monitored water vapor and other fluorinated compounds to compensate for interference. Tracer gas was sampled every two minutes, and sampling time varied per test and lasted a minimum of two hours.

The air within the living area of the houses was well-mixed by keeping the HVAC fan running continuously. Uniform mixing was verified by simultaneously sampling the tracer gas from the $1^{\text {st }}$ and $2^{\text {nd }}$ floors, and ensuring that their concentrations were within $10 \%$ of each other.

Confidence limits were determined by the method described in ASTM E 741-00 (Reapproved 2006), Standard Test Method for Determining Air Change in a Single Zone by Means of a Tracer 
Gas Dilution. The average confidence limit on AER was $+/-1.4 \%$ based on 56 samples from the summer 2012.

\subsection{Techniques to Reduce Formaldehyde Concentrations}

\subsubsection{Field Test Protocol}

Seven tests (T1 through T7) were conducted to examine the effectiveness of supply ventilation, exhaust ventilation, and gas-phase filtration in reducing formaldehyde concentrations. The timeline and locations where these tests took place are described in Table 1. The first two tests were pilot evaluations conducted in November 2011 and March 2012 in Houses 3 (T1-GF-H3 and T2-GF-H3) and House 4 (T1-GF-H4 and T2-GF-H4); the goal was to gather information that would help define the 2012 summer and fall experiments. This information included the amount of time it would take formaldehyde to reach a steady-state concentration after the mechanical ventilation or filtration system was turned on or off, as well as insight on the performance of the Shinyei monitors and filtration system. To this end, the air was sampled with DNPH cartridges and the Shinyei monitors before the system was in operation, while the system was running, and after the system was shut down. Air exchange rate, indoor temperature and relative humidity, and outdoor conditions were also monitored. After the pilot evaluations, eight-day experiments were outlined for the remaining tests as described in Table 2.

Table 1. Field test schedule.

\begin{tabular}{|c|c|c|c|c|}
\hline Test & Dates & House 2 & House 3 & House 4 \\
\hline $\begin{array}{c}1 \\
\text { (Pilot) }\end{array}$ & $11 / 21 / 11-11 / 28 / 11$ & - & $\begin{array}{c}\text { T1-GF-H3: } \\
\text { Gas-phase filtration }\end{array}$ & $\begin{array}{c}\text { T1-GF-H4: } \\
\text { Gas-phase filtration }\end{array}$ \\
\hline $\begin{array}{c}2 \\
\text { (Pilot) }\end{array}$ & $3 / 11 / 12-3 / 21 / 12$ & - & $\begin{array}{c}\text { T2-GF-H3: } \\
\text { Gas-phase filtration }\end{array}$ & $\begin{array}{c}\text { T2-GF-H4: } \\
\text { Gas-phase filtration }\end{array}$ \\
\hline 3 & $7 / 19 / 12-7 / 27 / 12$ & $\begin{array}{c}\text { T3-SV-H2: } \\
\text { Supply ventilation }\end{array}$ & $\begin{array}{c}\text { T3-SV-H3: } \\
\text { Supply ventilation }\end{array}$ & r \\
\hline 4 & $8 / 9 / 12-8 / 17 / 12$ & $\begin{array}{c}\text { T4-SV-H2: } \\
\text { Supply ventilation }\end{array}$ & $\begin{array}{c}\text { T4-SV-H3: } \\
\text { Supply ventilation }\end{array}$ & - \\
\hline 5 & $8 / 16 / 12-8 / 24 / 12$ & $\begin{array}{c}\text { T5-EV-H2: } \\
\text { Exhaust ventilation }\end{array}$ & ; & - \\
\hline 6 & $9 / 28 / 12-10 / 6 / 12$ & $\begin{array}{c}\text { T6-EV-H2: } \\
\text { Exhaust ventilation }\end{array}$ & $\begin{array}{c}\text { T6-EV-H3: } \\
\text { Exhaust ventilation }\end{array}$ & - \\
\hline 7 & $10 / 3 / 12-10 / 11 / 12$ & $\begin{array}{c}\text { T7-GF-H2: } \\
\text { Gas-phase filtration }\end{array}$ & $\begin{array}{c}\text { T7-GF-H3: } \\
\text { Gas-phase filtration }\end{array}$ & - \\
\hline \multicolumn{5}{|c|}{ Abbreviations: EV, exhaust ventilation; GF, gas-phase filtration; $\mathrm{H}$, house; SV, supply ventilation. } \\
\hline \multicolumn{5}{|c|}{$\begin{array}{l}\text { Tests } 3 \text { through Test } 7 \text { were performed in Houses } 2 \text { and } 3 \text {. House } 2 \text { was selected because it is } \\
\text { representative of more typical construction (i.e., } 2 \times 6 \text { studs at } 24 \text { " on center). House } 3 \text { was } \\
\text { chosen because preliminary surveys indicated that it had the highest formaldehyde } \\
\text { concentrations among the four homes. As described in Table } 1 \text {, Tests } 3 \text { and } 4 \text { involved supply } \\
\text { ventilation (T3-SV-H2, T3-SV-H3, T4-SV-H2, and T4-SV-H3); Tests } 5 \text { and } 6 \text { evaluated exhaust } \\
\text { ventilation (T5-EV-H2, T6-EV-H2, and T6-EV-H3); and Test } 7 \text { (T7-GF-H2 and T7-GF-H3) } \\
\text { examined gas-phase filtration. }\end{array}$} \\
\hline
\end{tabular}


Table 2. Experimental protocol for Tests 3 through 7.

\begin{tabular}{|c|c|}
\hline Day & Task \\
\hline 0 & $\begin{array}{l}\text { a. Shut down mechanical ventilation and cap outdoor air intake for at least one day before collecting background air } \\
\text { samples. These conditions remained during the entire filtration tests. } \\
\text { b. Tracer gas data collected while the mechanical ventilation was not in service was used to calibrate natural } \\
\text { ventilation rates estimated by EnergyPlus. }\end{array}$ \\
\hline 1 & Gather background formaldehyde concentrations, which is referred to as "before test" data in Table 4. \\
\hline 2 to 4 & $\begin{array}{l}\text { Measure decay (1-hr or 2-hr) and steady-state formaldehyde concentrations (24-hr) while the ventilation or filtration } \\
\text { system was running; this is referred to as "during test" data in Table } 4 .\end{array}$ \\
\hline 5 to 8 & $\begin{array}{l}\text { Collect buildup (1-hr or 2-hr) and steady-state formaldehyde concentrations (24-hr) after the ventilation or filtration } \\
\text { system was turned off, which is referred to "after test" data in Table } 4 .\end{array}$ \\
\hline
\end{tabular}

\subsubsection{Supply and Exhaust Ventilation}

Continuous supply and exhaust ventilation, without gas-phase filtration, were provided with a portable blower (Amaircare Airwash Whisper 675 or Lennox HEPA-60) that was attached to a window with a flex duct (Figure 1A). The airflow rate through the blower was regulated with a variable speed controller, and the air exchange rate produced by the blower was estimated with the whole-house tracer gas decay method.
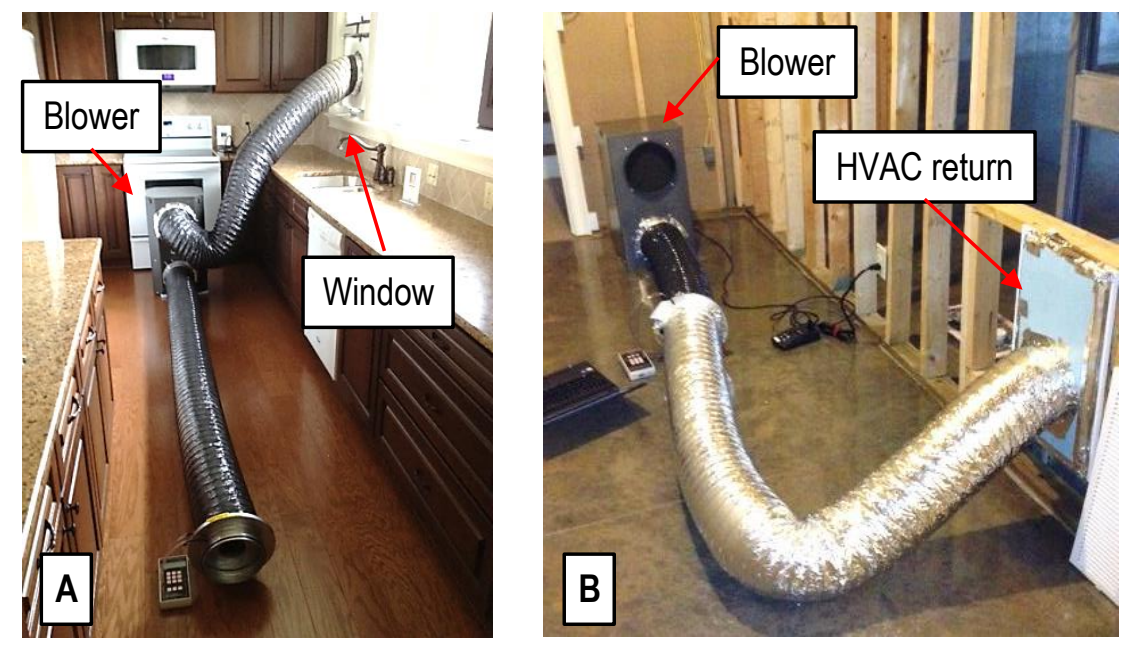

Figure 1. Mechanical ventilation and gas-phase filtration setup. A: Supply and exhaust ventilation was provided with a blower attached to a window. B: Air was treated by moving it through a blower with a filtration canister; the treated air was then supplied to the rest of the house through an existing HVAC return.

\subsubsection{Gas-Phase Filtration}

Air was treated in each house with gas-phase filters in portable blowers. Two blowers were used per house (Amaircare Airwash Whisper 675 or Lennox HEPA-60). Each blower had a canister with $13.6 \mathrm{~kg}$ of filtering material composed of activated coconut shell carbon with a proprietary additive to diminish formaldehyde concentrations. The blowers with the installed canisters and a carbon matt around the canisters were operated at a flow rate of about $375 \mathrm{cfm}$, with an average power usage of $0.54 \mathrm{~W} / \mathrm{cfm}$. The blower outlets were attached to the HVAC return grills so the central fan would distribute the filtered air throughout the houses (Figure 1B). The single-pass 
efficiency of the canisters was estimated by gathering air samples with DNPH cartridges upstream and downstream of the filtration unit. Additionally, the removal efficiency of the canisters was calculated using the decaying formaldehyde concentrations that were collected from the test houses immediately after filtration was initiated.

\subsection{Formaldehyde Concentration Estimates}

Equation 1 is the general mass balance equation for indoor formaldehyde concentration $\left(C_{i n}\right)$. This equation includes the effect from gas-phase filtration through the rate of clean air delivered $\left(\eta Q_{f}\right)$, and the net rate of formaldehyde adsorbed and desorbed $\left(R_{s}\right)$ into and out of storage or sink materials that act as secondary sources (i.e., materials that are not inherent sources of formaldehyde, but become secondary sources as this pollutant adsorbs and desorb from their surfaces). Equation 1a shows that $R_{s}$ is proportional to the difference between the equilibrium formaldehyde concentration at the surface of storage materials $\left(C_{e q}\right)$ and $C_{i n}$, the formaldehyde mass transfer coefficient $(K)$, and the surface area of the storage material where formaldehyde interacts $(A)$. Equation 2 was derived from Equation 1a to estimate $C_{\text {in }}$ as described in Appendix B. Equation 2 was simplified to Equation 3, where the source time constant, $K L$, in Equation 3 is due to the adsorption of formaldehyde onto storage materials as described in Appendix B.

Equation 3 indicates that in houses where the air exchange rate and the source time constant are comparable in magnitude, that these two variables can have similar influence on the amount of time it will take to reach steady-state concentrations during formaldehyde decay and buildup.

$$
\begin{aligned}
& V^{d C_{i n} / d t}=Q C_{\text {out }}+E-Q C_{\text {in }}-\eta Q_{f} C_{\text {in }}+R_{s} \\
& =Q C_{\text {out }}+E-Q C_{\text {in }}-\eta Q_{f} C_{\text {in }}-K\left(C_{\text {in }}-C_{\text {eq }}\right) A \\
& C_{\text {in }}(t)=C_{\text {in, } t=0}\left[e^{-\left(\lambda+\frac{\eta Q_{f}}{V}+K L\right) t}\right]+\left[\frac{\lambda C_{\text {out }}+E / V+K L C_{e q}}{\lambda+\frac{\eta Q_{f}}{V}+K L}\right]\left[1-e^{-\left(\lambda+\frac{\eta Q_{f}}{V}+K L\right) t}\right] \\
& C_{\text {in }}(t)=C_{\text {in }, t=0}\left[e^{-\left(\lambda+\frac{\eta Q_{f}}{V}+K L\right) t}\right]+C_{\text {in,ss }}\left[1-e^{-\left(\lambda+\frac{\eta Q_{f}}{V}+K L\right) t}\right]
\end{aligned}
$$

where

$C_{i n}(t)=$ indoor formaldehyde concentration as a function time ( $\left.\mathrm{ppb}\right)$

$C_{e q}=$ equilibrium formaldehyde concentration at boundary layer of emitting surface (ppb)

$C_{\text {out }}=$ outdoor formaldehyde concentration $(\mathrm{ppb})$

$C_{i n, t=0}=$ initial indoor formaldehyde concentration

$C_{i n, s s}=$ steady-state indoor formaldehyde concentration

$A=$ emitting surface area

$\lambda=A E R=$ air exchange rate $\left(\mathrm{h}^{-1}\right)$ due to natural and mechanical ventilation

$E=$ whole-house formaldehyde emission rate from primary sources $\left(\mathrm{ppb} \times \mathrm{m}^{3} / \mathrm{h}\right)$

$K=$ formaldehyde mass transfer coefficient of secondary sources such as storage materials $(\mathrm{m} / \mathrm{h})$

$L=$ loading factor or ratio of adsorbing/desorbing surface area to volume $\left(\mathrm{m}^{2} / \mathrm{m}^{3}\right)$

$K L=$ source time constant $\left(\mathrm{h}^{-1}\right)$

$\eta=$ filter removal efficiency 
$Q=$ ventilation rate $\left(\mathrm{m}^{3} / \mathrm{h}\right)$

$Q_{f}=$ flow rate through filtering device $\left(\mathrm{m}^{3} / \mathrm{h}\right)$

$R_{s}=$ net rate of formaldehyde sorption $(\mathrm{ppb} / \mathrm{h})$

$t=$ time (h)

$V=$ volume of occupied space $\left(\mathrm{m}^{3}\right)$

$\eta Q_{f}=\mathrm{CADR}=$ clean air delivery rate $=$ filtration system removal rate constant $\left(\mathrm{m}^{3} / \mathrm{h}\right)$

\subsection{Multivariate Regressions}

MatLab R2012a was used to conduct multivariate regressions and generate models that predict $C_{i n}$. Variables considered in the regressions were $T_{i n}$, outdoor temperature $\left(T_{\text {out }}\right)$, indoor relative humidity $\left(R H_{i n}\right)$, and ventilation rate (i.e., natural plus mechanical). Twenty-four hour averages were used with all of these variables except AER because its evaluation periods were shorter. Due to tight construction, AER measurements in these houses were relatively stable as long as mechanical ventilation rates remained the same and changes in outdoor conditions were not large. Sorption to storage materials and gas-phase filtration were not included in the regression models as this effort was beyond the scope of this project.

\subsection{Simulations}

EnergyPlus models were generated using version 7.2.0.006. Coefficients in EnergyPlus that are used by the software to estimate natural ventilation were calibrated with measured AERs. The derived multivariate equations were used with the calibrated EnergyPlus models to predict monthly formaldehyde concentrations, HVAC loads, and energy cost.

\section{Results and Discussion}

\subsection{Identification of Pollutants of Concern}

Mechanical ventilation in the studied homes was approximately $30 \mathrm{cfm}$ since their completion date in 2010, and during the 2011 exploratory air sampling surveys and pilot tests. Fresh air was provided through intermittent supply ventilation, and $30 \mathrm{cfm}$ is the average rate measured at the outdoor air intake with an airflow meter (Veltron DPT 2500). This AER is about half of what is required by ASHRAE 62.2-2010 in the tests homes (i.e., Houses 1 and $2=75 \mathrm{cfm}$, Houses 3 and $4=60 \mathrm{cfm}$ ). Low mechanical ventilation in conjunction with airtight envelopes slowed the decrease in pollutant concentration that is expected as indoor sources age, which partly explains some of the relatively high formaldehyde concentrations that follow.

Air samples were collected in Houses 3 and 4 in August 2011, and in all homes in November 2011 as part of the initial surveys to identify pollutants of concern. VOC and aldehyde concentrations from these surveys are presented in Appendix C. Results indicate that the monitored VOCs were well below the recommended exposure levels (REL) set by the National Institute for Occupational Safety and Health (NIOSH) and/or the state of California Office of Environmental and Health Hazard Assessment (OEHHA). This is likely because many of the typical sources that emit these compounds (e.g., gasoline, solvents, fragrances, cleaners) are not present in unoccupied houses in significant quantities. However, relatively elevated 
concentrations of acetic acid were detected, especially in House 1 (178 ppb). The probable source was silicone caulk that was used to seal the building envelope.

Among the aldehydes that were monitored in these exploratory surveys, only formaldehyde exceeded the RELs set by NIOSH (8-hr exposure: $16 \mathrm{ppb)}$ and OEHHA (8-hr exposure: 7.3 $\mathrm{ppb})$, which are the strictest recommended levels worldwide. Other RELs include: Canada $=40$ ppb (8-hr), Norway $=50 \mathrm{ppb}(24-\mathrm{hr})$, and World Health Organization $(\mathrm{WHO})=81 \mathrm{ppb}(30-$ minute). Formaldehyde concentrations in August were $172 \mathrm{ppb}$ in House 3 and $73 \mathrm{ppb}$ in House 4. In November, these were 22, 49, 112 and 44 ppb in Houses 1, 2, 3 and 4, respectively. Consequently, it was determined that formaldehyde would be used as an indicator of adequate indoor air quality throughout this research. This is in agreement with recommendations by Sherman and Hodgson (2004), who stated that this compound could be utilized as a basis for residential ventilation rates given its pervasiveness indoors. Although several attempts were made to collect 24-hr outdoor air samples, many of these were unsuccessful because high humidity congealed the silica gel in the DNPH cartridges. The few successful measurements yielded outdoor concentrations of about $2 \mathrm{ppb}$.

\section{2 $\quad$ Pilot Tests}

The Pilot Tests Section and the following one, 3.3 Summer and Fall Tests, primarily focus on the data gathered during these evaluations. Subsequent Sections combine data from the pilot, summer and fall tests, and examine them with regard to potential formaldehyde sources and the effects from sorption kinetics, ventilation and gas-phase filtration.

Table 3 describes the environmental conditions during the pilot assessments that were conducted in Houses 3 and 4 in November 2011 (T1-GF-H3 and T1-GF-H4) and March 2012 (T2-GF-H3 and T2-GF-H4). In this Table "before test" data were collected a few days prior to the evaluation to serve as baseline values, and "during test" data are primarily 24-hr averages gathered 3 days after gas-phase filtration had begun. In November, average indoor temperatures remained close to $22^{\circ} \mathrm{C}$ before and during the tests, while $R H_{\text {in }}$ decreased in both homes. In March, $T_{\text {in }}$ increased by up to $2^{\circ} \mathrm{C}$ during the test in Houses 3 and 4 , while $R H_{\text {in }}$ changed significantly in House 3 from $34 \%$ to $44 \%$. 
Table 3. Formaldehyde concentrations and environmental conditions during pilot tests Tests 1 and 2 in Houses 3 and 4 .

\begin{tabular}{|c|c|c|c|c|c|c|}
\hline \multirow[b]{2}{*}{ Measurement } & \multicolumn{2}{|c|}{ House 3} & \multicolumn{2}{|c|}{ House 4} & \multicolumn{2}{|c|}{ Outdoors } \\
\hline & $\begin{array}{c}\text { Before } \\
\text { test }\end{array}$ & $\begin{array}{c}\text { During } \\
\text { test }\end{array}$ & $\begin{array}{c}\text { Before } \\
\text { test }\end{array}$ & $\begin{array}{c}\text { During } \\
\text { test }\end{array}$ & $\begin{array}{c}\text { Before } \\
\text { test }\end{array}$ & $\begin{array}{c}\text { During } \\
\text { test }\end{array}$ \\
\hline \multicolumn{7}{|c|}{ T1-GF: Test 1, gas-phase filtration } \\
\hline Dates & $11 / 21-11 / 22$ & $11 / 25-11 / 26$ & $11 / 21-11 / 22$ & $11 / 26-11 / 27$ & $11 / 21-11 / 22$ & $11 / 26-11 / 27$ \\
\hline$C_{i n}(\mathrm{ppb})$ & 112 & 22 & 44 & 18 & - & - \\
\hline$T_{\text {in }}, T_{\text {out }}\left({ }^{\circ} \mathrm{C}\right)$ & $21.7 \pm 0.5$ & $21.7 \pm 0.3$ & $22.3 \pm 0.4$ & $22.3 \pm 0.5$ & $15.8 \pm 2.7$ & $9.1 \pm 3.8$ \\
\hline$R H_{\text {in }}, R H_{\text {out }}(\%)$ & $50.0 \pm 2.1$ & $42.3 \pm 1.2$ & $51.8 \pm 1.6$ & $46.5 \pm 0.6$ & $72.2 \pm 12.7$ & $72.5 \pm 18.7$ \\
\hline $\operatorname{AER}\left(h^{-1}\right)$ & 0.14 & 0.14 & 0.07 & 0.15 & - & - \\
\hline Ventilation (cfm) & 67 & 67 & 33 & 71 & - & - \\
\hline \multicolumn{7}{|c|}{ T2-GF: Test 2, gas-phase filtration } \\
\hline Dates & $3 / 10-3 / 11$ & $3 / 16-3 / 17$ & $3 / 10-3 / 11$ & $3 / 16-3 / 17$ & $3 / 10-3 / 11$ & $3 / 16-3 / 17$ \\
\hline$C_{\text {in }}(\mathrm{ppb})$ & 64 & 46 & 23 & 16 & - & - \\
\hline$T_{\text {in }}, T_{\text {out }}\left({ }^{\circ} \mathrm{C}\right)$ & $21.7 \pm 0.5$ & $23.9 \pm 0.4$ & $22.1 \pm 0.7$ & $23.6 \pm 0.7$ & $9.5 \pm 6.6$ & $16.4 \pm 3.9$ \\
\hline$R H_{\text {in }}, R H_{\text {out }}(\%)$ & $33.7 \pm 1.4$ & $43.5 \pm 1.6$ & NA & NA & $52.8 \pm 25.5$ & $88.7 \pm 18.7$ \\
\hline $\operatorname{AER}\left(h^{-1}\right)$ & 0.16 & 0.16 & 0.2 & 0.09 & - & - \\
\hline Ventilation (cfm) & 73 & 73 & 95 & 43 & - & - \\
\hline
\end{tabular}

a. All reported values are 24-hr averages except air exchange or ventilation rates. Standard deviations are shown for temperature and relative humidity values.

b. Volumes: Houses 3 and $4=805 \mathrm{~m}^{3}\left(28,406 \mathrm{ft}^{3}\right)$.

c. Average intermittent mechanical ventilation before and during test $=30 \mathrm{cfm}$.

Abbreviations: $A E R$, air exchange rate due to natural and mechanical ventilation; $C_{i n}$, indoor formaldehyde concentration; $R H_{i n}$, indoor relative humidity; $R H_{\text {out }}$, outdoor relative humidity; $T_{i n}$, indoor temperature; $T_{\text {out }}$, outdoor temperature,

Due to gas-phase filtration, 24-hr DNPH measurements indicate that formaldehyde in House 3 decreased from 112 to $22 \mathrm{ppb}$ in November, and from 62 to $46 \mathrm{ppb}$ in March; whereas House 4 indicated lower reductions: 44 to $18 \mathrm{ppb}$ and 23 to $16 \mathrm{ppb}$, respectively. Figures 2A, 3A, 3B and especially $2 \mathrm{~B}$ suggest minimal correlation between $T_{i n}$ and the Shinyei formaldehyde measurements, which is inconsistent with findings from various researchers (Matthews et al. 1984; Meyer and Hermanns 1985; and Myers 1985).

The observed decreases in formaldehyde during the pilot tests, especially in House 3, hinted that the off-the-shelf filtration system was worth additional evaluation during the summer and fall tests. Additionally, after the pilot tests it was decided that 1-hr and 2-hr DNPH samples would be collected during the formaldehyde decay and buildup to characterize these short-term events. These DNPH measurements were also intended to further evaluate Shinyei data. 
$\diamond \mathrm{HCHO}$ Shinyei $\quad \diamond 24-\mathrm{hr} \mathrm{HCHO}$ DNPH $\quad-T_{\text {in }}$

- - Model estimates using Shinyei data and $K L=0 \quad$ - Model estimates using Shinyei data and $K L=0.18$
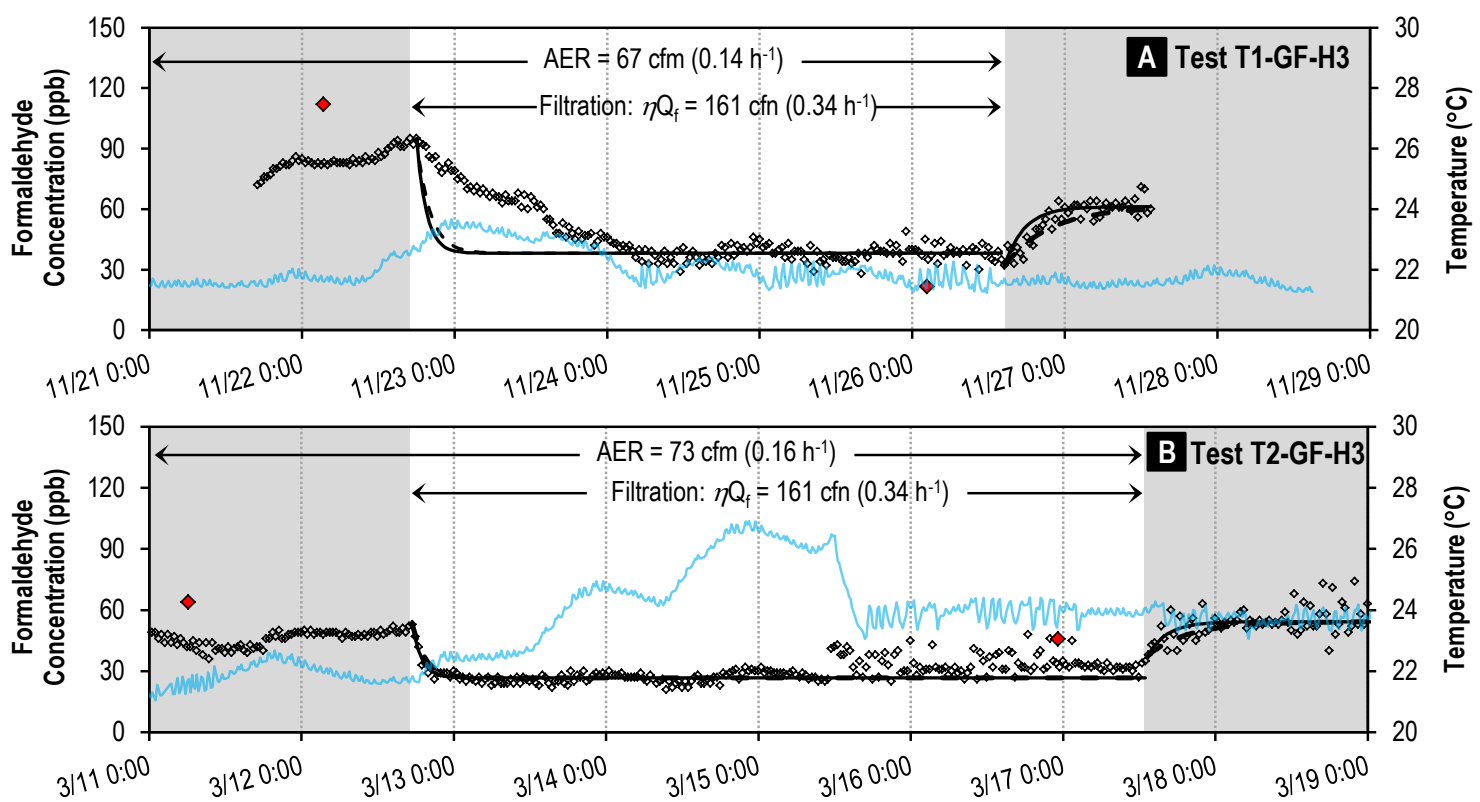

Figure 2. House 3 measurements during pilot Tests 1 and 2.

a. DNPH concentrations are shown halfway through the sampling period.

b. Air exchange rates shown were due to natural and mechanical ventilation.

c. $\mathrm{HCHO}$ stands for formaldehyde. $K L$ is the combined time constant of all storage materials.

$\diamond \mathrm{HCHO}$ Shinyei $\quad \diamond 24-\mathrm{hr} \mathrm{HCHO}$ DNPH $\quad-T_{\text {in }}$

- - Model estimates using Shinyei data and $K L=0 \quad$ - Model estimates using Shinyei data and $K L=0.18$
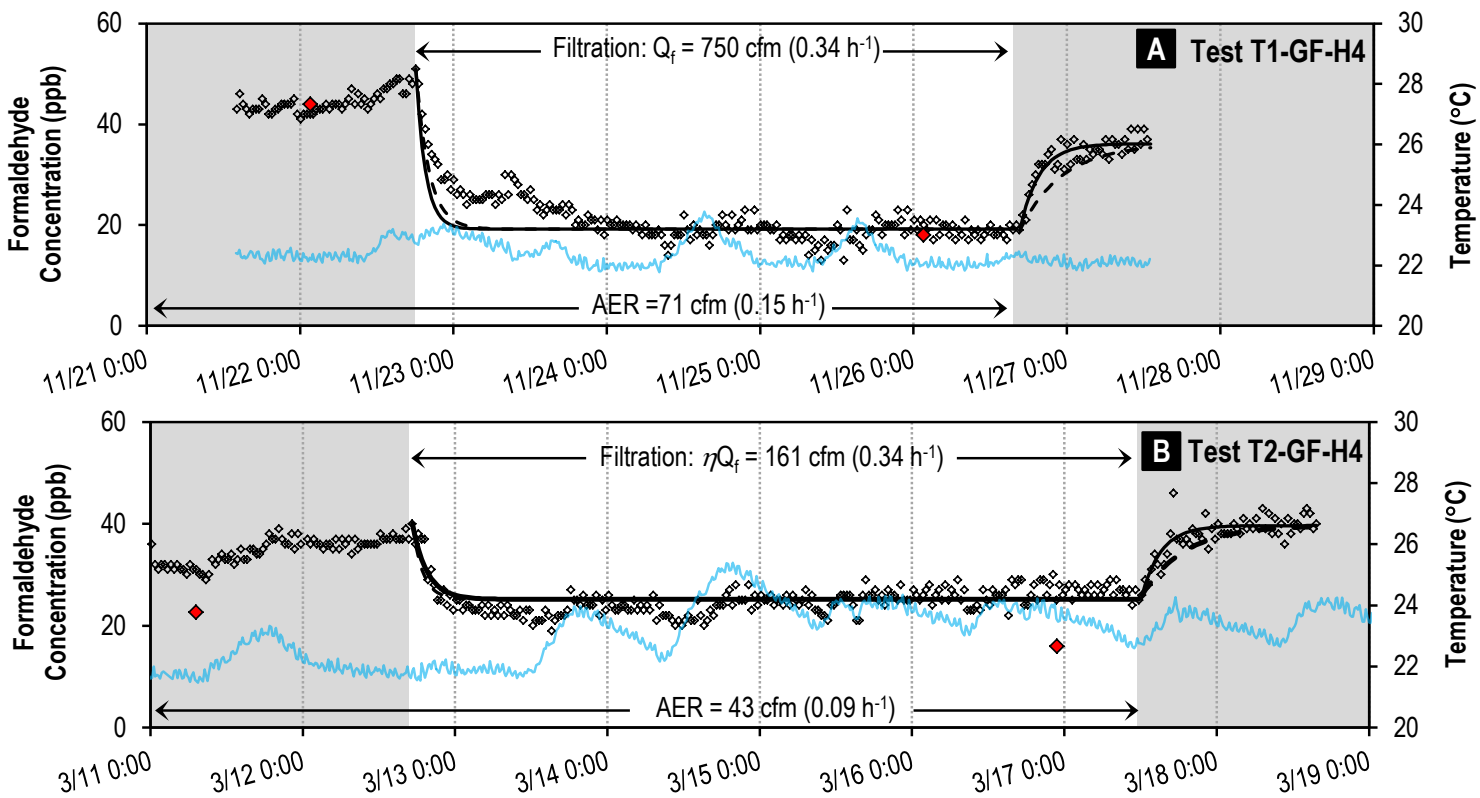

Figure 3. House 4 measurements during pilot Tests 1 and 2.

a. DNPH concentrations are shown halfway through the sampling period.

b. Air exchange rates shown were due to natural and mechanical ventilation.

c. $\mathrm{HCHO}$ stands for formaldehyde. $K L$ is the combined time constant of all storage materials. 


\subsection{Summer and Fall Tests}

Table 4 summarizes data collected from Houses 2 and 3 during the summer and fall experiments, and Figures 4 and 5 illustrate some of these results. Table 4 lists DNPH measurements that were gathered about 24 hours before the test, 48 hours into the test, and 48 hours after the test. Figures 4 and 5 show these data and additional 1-hr, 2-hr and 24-hr DNPH measurements that were collected to examine the decay and buildup of formaldehyde. Data in Table 4 are daily averages, except for AER because its sampling periods were shorter. In general, changes in $T_{\text {in }}$ did not exceed $1{ }^{\circ} \mathrm{C}$. An exception occurred during Test T3-SV-H2 when the HVAC system in House 2 was not working properly. Indoor moisture appeared to have been influenced by ventilation given that $R H_{\text {in }}$ showed increases of up to 5\% with higher AER. Additionally, $R H_{\text {in }}$ in both homes was typically above 50\% likely because outdoor humidity is usually high in Oak Ridge, TN, during this time of the year and latent loads are difficult to control without a dedicated dehumidifier. Moreover, the air handling unit was running continuously during the tests, which can increase humidity by re-evaporating moisture that remains on the evaporating coils after the compressor shuts down. Outdoor conditions were somewhat typical for the area, with $T_{\text {out }}$ ranging from 21.2 to $26.4^{\circ} \mathrm{C}$ in the summer, and from 9.6 to $23.6^{\circ} \mathrm{C}$ in the fall, which include lower temperatures during Test 7 due to a cold font. Outdoor $R H$ was relatively high during several of the tests because of rain.

\subsubsection{Tests 3 and 4: Supply Ventilation}

Tests 3 and 4 involved investigating the effect of supply ventilation on formaldehyde concentrations. Figure 4A shows the results from Test T3-SV-H2 in House 2. Here, ventilation rates were increased from 14 to $157 \mathrm{cfm}\left(0.02\right.$ to $\left.0.21 \mathrm{~h}^{-1}\right)$, which led to a decrease in $C_{i n}$ from 86 to $23 \mathrm{ppb}$. However, this reduction in concentration was influenced by the simultaneous drop in $T_{\text {in }}$ due to malfunctioning of the HVAC system. DNPH and Shinyei data on Figure 4A illustrate the dependence of formaldehyde concentrations and emission rates on temperature, which has been documented by Matthews et al. (1984), Meyer and Hermanns (1985), and Myers (1985). Test T3-SV-H3 in House 3 changed ventilation from 60 to $159 \mathrm{cfm}\left(0.13\right.$ to $\left.0.34 \mathrm{~h}^{-1}\right)$, which caused a decay in $C_{i n}$ from 169 to $97 \mathrm{ppb}$ as shown in Figure 5A.

Higher AERs were used in Test 4 than in Test 3 to obtain a larger range of data points for the regression analyses. Test 4 involved increasing AER in House 2 from 15 to $284 \mathrm{cfm}(0.02$ to $\left.0.38 \mathrm{~h}^{-1}\right)$, and in House 3 from 51 to $227 \mathrm{cfm}\left(0.11\right.$ to $\left.0.48 \mathrm{~h}^{-1}\right)$. Decreases in $C_{\text {in }}$ in these homes went from 55 to $24 \mathrm{ppb}$ and 173 to $59 \mathrm{ppb}$, respectively. Results are depicted in Figures 4B and $5 \mathrm{~B}$, where the latter shows 2-hr concentrations that were collected during the formaldehyde buildup that were up to 1.5 times higher than the 24-hr values. It is possible that these short-term measurements are not correct because low formaldehyde concentrations must have also occurred in order to obtain the measured 24-hr values, and because there were no major increases in $T_{\text {in }}$ that could have led to higher $C_{i n}$. Unfortunately, the sensor in the Shinyei monitor malfunctioned and data are not available to corroborate these high formaldehyde DNPH measurements. 
Table 4. Formaldehyde concentrations and environmental conditions during Tests 3 through 7 in Houses 2 and 3.

\begin{tabular}{|c|c|c|c|c|c|c|c|c|c|}
\hline \multirow{2}{*}{ Measurement } & \multicolumn{3}{|c|}{ House 2} & \multicolumn{3}{|c|}{ House 3} & \multicolumn{3}{|c|}{ Outdoors } \\
\hline & $\begin{array}{c}\text { Before } \\
\text { test }\end{array}$ & $\begin{array}{c}\text { During } \\
\text { test }\end{array}$ & After test & $\begin{array}{c}\text { Before } \\
\text { test }\end{array}$ & $\begin{array}{c}\text { During } \\
\text { test }\end{array}$ & After test & $\begin{array}{c}\text { Before } \\
\text { test }\end{array}$ & $\begin{array}{c}\text { During } \\
\text { test }\end{array}$ & After test \\
\hline \multicolumn{10}{|c|}{ T3-SV: Test 3, supply ventilation } \\
\hline Dates & $7 / 19-7 / 20$ & $7 / 21-7 / 22^{b}$ & $7 / 25-7 / 26$ & $7 / 19-7 / 20$ & $7 / 22-7 / 23$ & $7 / 25-7 / 26$ & $7 / 19-7 / 20$ & $7 / 22-7 / 23$ & $7 / 25-7 / 26$ \\
\hline$C_{i n}(\mathrm{ppb})$ & 86 & 23 & 45 & 169 & 97 & 167 & - & - & - \\
\hline$T_{\text {in }}, T_{\text {out }}\left({ }^{\circ} \mathrm{C}\right)$ & $26.9 \pm 1.2$ & $24.0 \pm 0.4$ & $24.3 \pm 1.0$ & $23.5 \pm 0.8$ & $23.4 \pm 1.2$ & $23.4 \pm 1.1$ & $26.4 \pm 2.4$ & $27.0 \pm 3.7$ & $29.1 \pm 3.2$ \\
\hline$R H_{\text {in }}, R H_{\text {out }}(\%)$ & $48.3 \pm 1.4$ & $58.8 \pm 3.6$ & $47.8 \pm 3.2$ & $59.1 \pm 3.8$ & $63.7 \pm 6.1$ & $58.3 \pm 4.7$ & $89.2 \pm 27.7$ & $77.5 \pm 31.4$ & $69.0 \pm 21.4$ \\
\hline $\operatorname{AER}\left(h^{-1}\right)$ & $0.02^{c}$ & 0.21 & $0.02^{c}$ & $0.13^{b}$ & 0.34 & $0.13^{c}$ & - & - & - \\
\hline Ventilation (cfm) & $14^{c}$ & 157 & $16^{c}$ & $60^{b}$ & 159 & $60^{c}$ & - & - & - \\
\hline \multicolumn{10}{|c|}{ T4-SV: Test 4, supply ventilation } \\
\hline Dates & $8 / 9-8 / 10$ & $8 / 12-8 / 13$ & $8 / 15-8 / 16$ & $8 / 9-8 / 10$ & $8 / 12-8 / 13$ & $8 / 15-8 / 16$ & $8 / 9-8 / 10$ & $8 / 12-8 / 13$ & $8 / 15-8 / 16$ \\
\hline$C_{\text {in }}(\mathrm{ppb})$ & 55 & 24 & 56 & 173 & 59 & 157 & - & - & - \\
\hline$T_{\text {in }}, T_{\text {out }}\left({ }^{\circ} \mathrm{C}\right)$ & $24.2 \pm 0.4$ & $23.8 \pm 0.4$ & $24.2 \pm 0.5$ & $23.6 \pm 0.8$ & $23.5 \pm 0.8$ & $23.6 \pm 0.8$ & $22.4 \pm 2.8$ & $21.2 \pm 4.3$ & $23.0 \pm 4.1$ \\
\hline$R H_{\text {in }}, R H_{\text {out }}(\%)$ & $49.6 \pm 1.2$ & $56.2 \pm 3.3$ & $51.4 \pm 1.8$ & $62.5 \pm 3.8$ & $59.5 \pm 4.1$ & $60.6 \pm 4.2$ & $100-32.3$ & $80.9 \pm 39.3$ & $92.0 \pm 43.4$ \\
\hline $\operatorname{AER}\left(h^{-1}\right)$ & $0.02^{c}$ & 0.38 & $0.02^{c}$ & $0.11^{c}$ & 0.48 & $0.12^{c}$ & - & - & - \\
\hline Ventilation (cfm) & $15^{c}$ & 284 & $12^{b}$ & $51^{c}$ & 227 & $56^{c}$ & - & - & - \\
\hline \multicolumn{10}{|c|}{ T5-EV: Test 5, exhaust ventilation } \\
\hline Dates & $8 / 16-8 / 17$ & $8 / 19-8 / 20$ & $8 / 23-8 / 24$ & - & - & - & $8 / 16-8 / 17$ & $8 / 19-8 / 20$ & $8 / 23-8 / 24$ \\
\hline$C_{\text {in }}(\mathrm{ppb})$ & 58 & 67 & 59 & - & - & - & - & - & - \\
\hline$T_{\text {in }}, T_{\text {out }}\left({ }^{\circ} \mathrm{C}\right)$ & $24.2 \pm 0.5$ & $24.2 \pm 0.5$ & $24.2 \pm 0.5$ & - & - & - & $23.6 \pm 4.0$ & $20.9 \pm 3.8$ & $22.6 \pm 5.2$ \\
\hline$R H_{\text {in }}, R H_{\text {out }}(\%)$ & $50.9 \pm 1.6$ & $54.6 \pm 3.4$ & $50.9 \pm 1.6$ & - & - & - & $74.5 \pm 29.0$ & $99.9 \pm 36.1$ & $72.9 \pm 37.1$ \\
\hline $\operatorname{AER}\left(h^{-1}\right)$ & $0.01 c$ & 0.16 & $0.021^{c}$ & - & - & - & - & - & - \\
\hline Ventilation (cfm) & 9c & 118 & $16^{c}$ & - & - & - & - & - & - \\
\hline \multicolumn{10}{|c|}{ T6-EV: Test 6, exhaust ventilation } \\
\hline Dates & $9 / 28-9 / 29$ & $10 / 1-10 / 2$ & $10 / 3-10 / 4$ & $9 / 28-9 / 29$ & $10 / 1-10 / 2$ & $10 / 3-10 / 4$ & $9 / 28-9 / 29$ & $10 / 1-10 / 2$ & $10 / 3-10 / 4$ \\
\hline$C_{i n}(\mathrm{ppb})$ & 61 & 49 & 47 & 135 & 122 & 168 & - & - & - \\
\hline$T_{\text {in }}, T_{\text {out }}\left({ }^{\circ} \mathrm{C}\right)$ & $24.0 \pm 0.4$ & $23.1 \pm 0.5$ & $23.9 \pm 0.4$ & $23.7 \pm 0.7$ & $23.4 \pm 0.5$ & $23.8 \pm 0.5$ & $21.1 \pm 2.4$ & $17.9 \pm 1.7$ & $17.5 \pm 3.5$ \\
\hline$R H_{\text {in }}, R H_{\text {out }}(\%)$ & $54.3 \pm 1.3$ & $53.4 \pm 2.4$ & $57.4 \pm 1.2$ & $59.8 \pm 3.5$ & $58.3 \pm 2.6$ & $59.8 \pm 2.8$ & $89.5 \pm 13.6$ & $100-0.4$ & $80.3 \pm 19.1$ \\
\hline $\operatorname{AER}\left(h^{-1}\right)$ & $0.02^{c}$ & 0.21 & $0.037^{c}$ & $0.10^{c}$ & 0.35 & $0.124^{c}$ & - & - & - \\
\hline Ventilation (cfm) & $13^{c}$ & 160 & $28^{c}$ & $50^{c}$ & 165 & $59 c$ & - & - & - \\
\hline \multicolumn{10}{|c|}{ T7-GF: Test 7, gas-phase filtration } \\
\hline Dates & $10 / 3-10 / 4$ & $10 / 7-10 / 8$ & $10 / 9-10 / 10$ & $10 / 3-10 / 4$ & $10 / 7-10 / 8$ & $10 / 9-10 / 10$ & $10 / 3-10 / 4$ & $10 / 7-10 / 8$ & $10 / 9-10 / 10$ \\
\hline$C_{\text {in }}(\mathrm{ppb})$ & 47 & 16 & 53 & 168 & 61 & 85 & - & - & - \\
\hline$T_{\text {in }}, T_{\text {out }}\left({ }^{\circ} \mathrm{C}\right)$ & $23.9 \pm 0.4$ & $22.4 \pm 0.4$ & $22.0 \pm 0.4$ & $23.8 \pm 0.5$ & $22.7 \pm 0.5$ & $21.3 \pm 0.6$ & $17.5 \pm 3.5$ & $9.6 \pm 1.8$ & $9.8 \pm 3$ \\
\hline$R H_{\text {in }}, R H_{\text {out }}(\%)$ & $57.4 \pm 1.2$ & $56.9 \pm 0.6$ & $56.7 \pm 1.0$ & $59.8 \pm 2.8$ & $52.9 \pm 1.2$ & $51.8 \pm 2.1$ & $80.3 \pm 19.1$ & $81.7 \pm 14.6$ & $86.7 \pm 15.1$ \\
\hline $\operatorname{AER}\left(h^{-1}\right)$ & $0.04^{b}$ & $0.05^{c}$ & $0.05^{c}$ & $0.12^{c}$ & $0.12^{c}$ & $0.13^{c}$ & - & - & - \\
\hline Ventilation (cfm) & $28^{c}$ & $36^{c}$ & $40^{\circ}$ & $56^{c}$ & $55^{c}$ & $63^{c}$ & - & - & - \\
\hline
\end{tabular}

a. All reported values are $24-\mathrm{hr}$ averages except air exchange or ventilation rates.

b. Reported data from 7/21-7/22 instead of 7/22-7/23 because HVAC malfunctioned on 7/22 and $T_{\text {in }}$ was not properly controlled.

c. Mechanical ventilation shut down and outdoor intake capped.

d. Volumes: House $2=1,280 \mathrm{~m}^{3}\left(45,168 \mathrm{ft}^{3}\right)$; Houses $3=805 \mathrm{~m}^{3}\left(28,406 \mathrm{ft}^{3}\right)$. 


\subsubsection{Tests 5 and 6: Exhaust Ventilation}

Tests 5 and 6 explored the influence of exhaust ventilation on formaldehyde. In House 2, ventilation was increased from 9 to $118 \mathrm{cfm}\left(0.01\right.$ to $\left.0.16 \mathrm{~h}^{-1}\right)$ in Test T5-EV-H2, and from 13 to $160 \mathrm{cfm}\left(0.02\right.$ to $\left.0.21 \mathrm{~h}^{-1}\right)$ in Test T6-EV-H2. Results in Table 4, and Figures 4C and 4D, indicate that exhaust ventilation had minimal effect on formaldehyde concentrations as no clear decay or buildup was observed. Exhaust ventilation may have been somewhat more effective in House 3; however, these findings are inconclusive because the Shinyei monitor malfunctioned during the experiment. In Test T6-EV-H3, ventilation was increased from 50 to $165 \mathrm{cfm}(0.1$ to $0.35 \mathrm{~h}^{-1}$ ), which led to a reduction of $C_{\text {in }}$ from 135 to $122 \mathrm{ppb}$. The 1-hr DNPH measurements suggest a decay and buildup, but these trends are not as evident as in the supply ventilation and filtration tests. Supply ventilation may be more successful than exhaust ventilation in reducing formaldehyde that originates from the building envelope because the former generates airflows that take pollutants within the cavities of exterior walls directly outdoors. In contrast, exhaust ventilation can create airflows that transport pollutants within the cavity of exterior walls into the living area, which would make dilution of indoor contaminants with fresh air less effective. Rudd and Bergey (2013) also reported similar results on the lower performance of exhaust ventilation. More research is needed to evaluate exhaust ventilation given that, among the various types of residential mechanical ventilation systems, exhaust ventilation is likely the most popular because it can be attained economically with bathroom fans.

\subsubsection{Test 7: Gas-Phase Filtration}

Test 7 was a continuation of the pilot evaluations that focused on gas-phase filtration. In House 2 , formaldehyde decreased from 47 to $16 \mathrm{ppb}$. Natural ventilation remained relatively uniform ranging between 28 and $40 \mathrm{cfm}\left(0.04\right.$ to $\left.0.05 \mathrm{~h}^{-1}\right)$; mechanical ventilation was not used. We obtained similar findings in House 3: $C_{\text {in }}$ decreased from 168 to $61 \mathrm{ppb}$, with relatively steady natural ventilation ranging from 55 to $63 \mathrm{cfm}\left(0.12\right.$ to $\left.0.13 \mathrm{~h}^{-1}\right)$. Figures $4 \mathrm{E}$ and $5 \mathrm{D}$ indicate a drop in $T_{\text {in }}$ of at least $2{ }^{\circ} \mathrm{C}$ due to a cold front that caused $T_{\text {out }}$ to steadily decrease from $26^{\circ} \mathrm{C}$ on October 5 to $8^{\circ} \mathrm{C}$ on October 8. As in the pilot tests, formaldehyde measurements from the Shinyei monitors did not show much of a dependency on indoor temperature during gas-phase filtration. 
$\diamond \mathrm{HCHO}$ Shinyei $\quad \diamond 24-\mathrm{hr} \mathrm{HCHO}$ DNPH $\quad \diamond 2$-hr HCHO DNPH $\diamond 1$-hr HCHO DNPH $\quad-T_{\text {in }}$

- Model estimates using Shinyei data and $K L=0 \quad$ - Model estimates using Shinyei data and $K L=0.15$

- Model estimates using DNPH data and $K L=0 \quad$ - Model estimates using DNPH data and $K L=0.15$
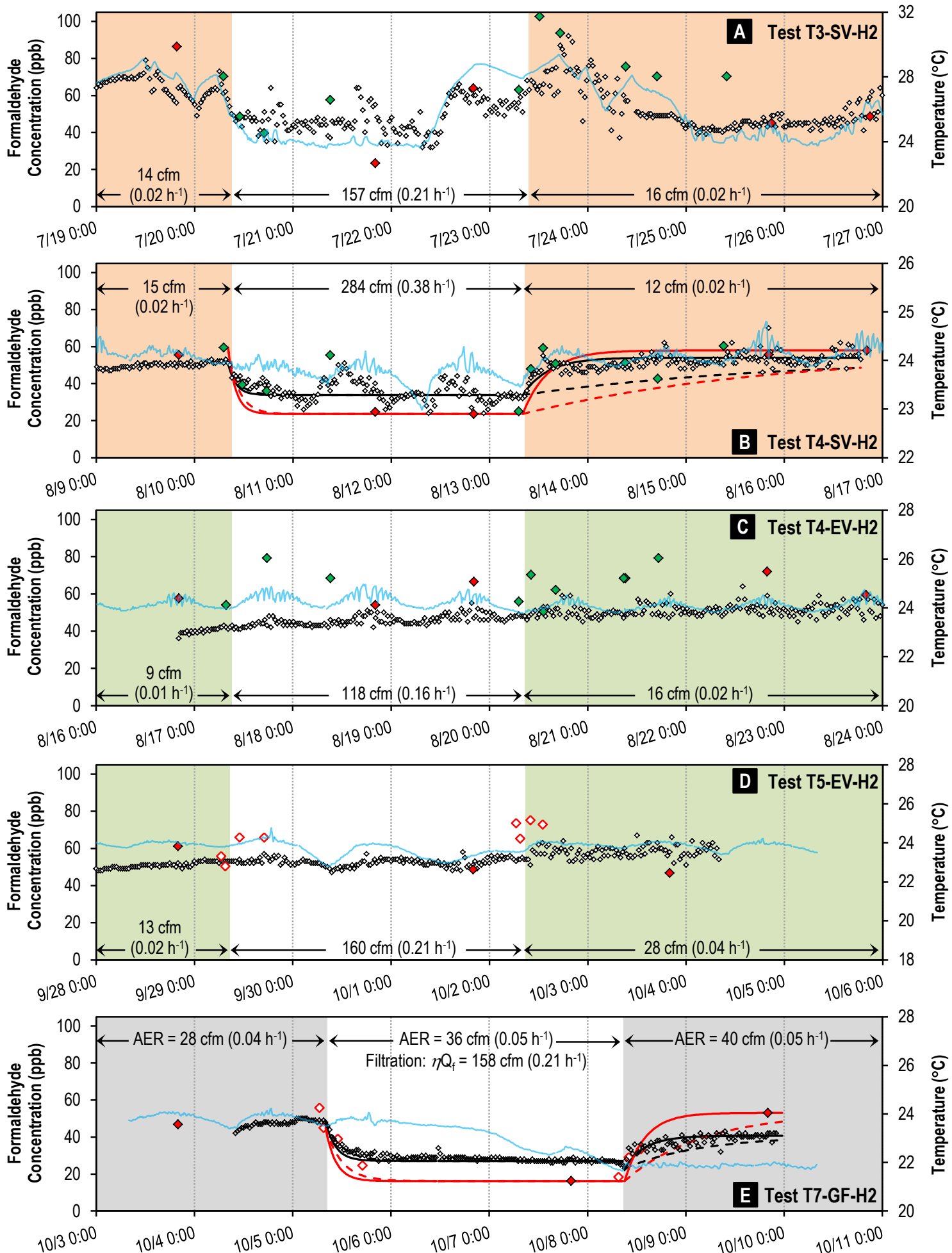

Figure 4. House 2 measurements during Tests 3 through 7.

a. Figures 4A and 4B: supply ventilation; 4C and 4D: exhaust ventilation; 4E: gas-phase filtration.

b. DNPH concentrations are shown halfway through the sampling period.

c. Air exchange rates shown were due to natural and mechanical ventilation.

d. $\mathrm{HCHO}$ stands for formaldehyde. $K L$ is the combined time constant of all storage materials. 

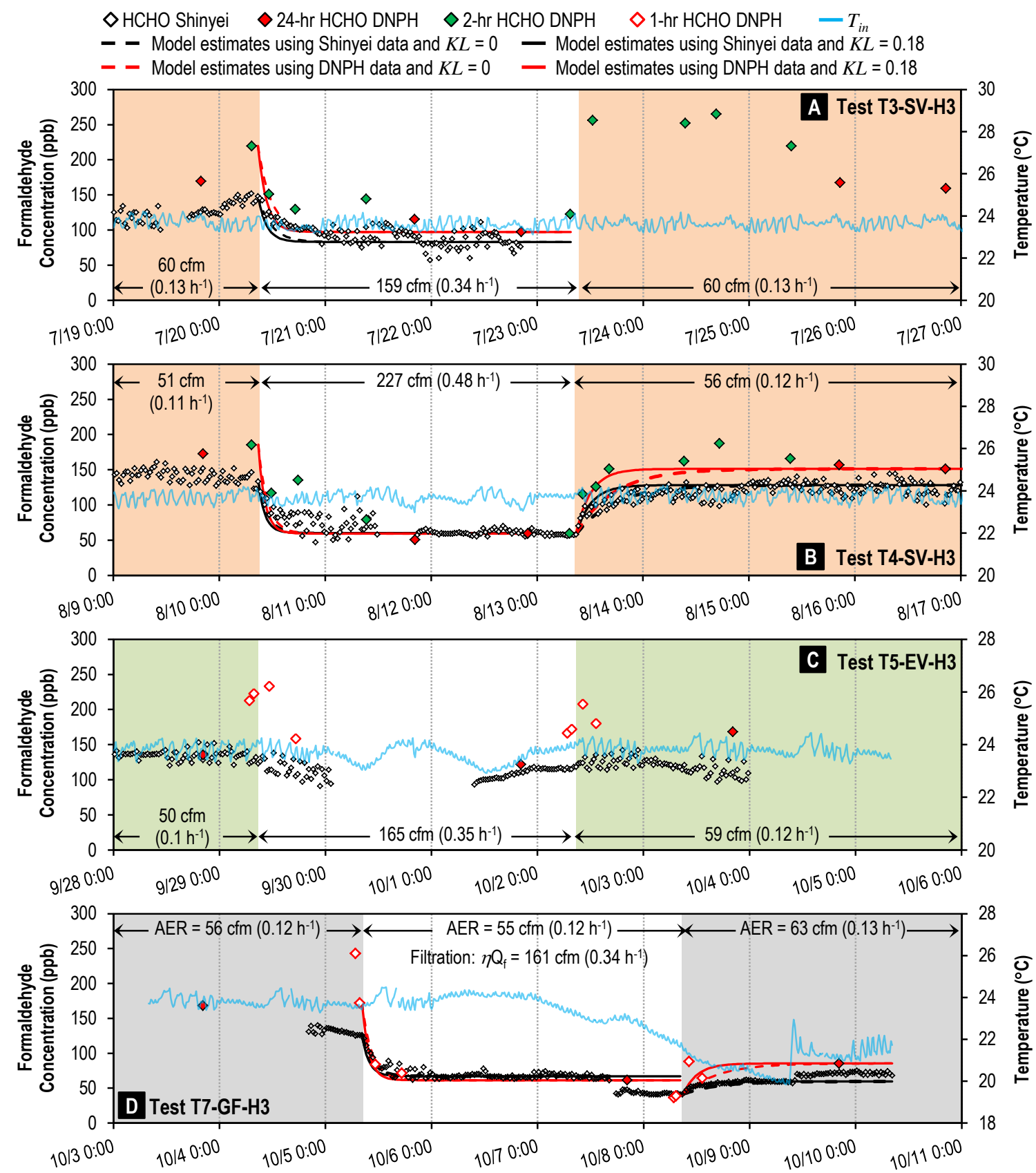

Figure 5. House 3 measurements during Tests 3, 4, 6 and 7.

a. Figures 5A and 5B: supply ventilation; 5C: exhaust ventilation; 5D: gas-phase filtration.

b. DNPH concentrations are shown halfway through the sampling period.

c. Air exchange rates shown were due to natural and mechanical ventilation.

d. HCHO stands for formaldehyde. $K L$ is the combined time constant of all storage materials. 


\subsection{Formaldehyde Sources}

Emission rates from formaldehyde sources varied with seasonal changes in the four studied homes. Figure 6 summarizes $C_{i n}$ values that were collected in between tests, where mechanical ventilation systems were set to $30 \mathrm{cfm}$ (Houses 1 and $2=0.04 \mathrm{~h}^{-1}$, Houses 3 and $4=0.06 \mathrm{~h}^{-1}$ ) during the 2011 and winter 2012 data surveys, and shut down while the summer and fall 2012 measurements were gathered. Additionally, daily average $T_{\text {in }}$ ranged from $22^{\circ} \mathrm{C}$ (fall and winter) to $24^{\circ} \mathrm{C}$ (summer); and outdoor temperatures ranged from $0.6^{\circ} \mathrm{C}$ to $33.1^{\circ} \mathrm{C}$, with daily averages spanning from $9.5^{\circ} \mathrm{C}$ to $26.4^{\circ} \mathrm{C}$. Results in Figure 6 indicate that $C_{i n}$ progressively increased from the cooler to the warmer months by about $50 \%$, which likely occurred because emission rates from sources increase with temperature. Hawthorne et al. (1986), and Sekine and Nishimura (2001) noted similar formaldehyde seasonal changes in new homes. Although relative humidity is also an influential factor on emission rates, its effects are more difficult to capture in field tests because it can take days or weeks for formaldehyde emissions from sources, such as composite wood, to reach equilibrium after a change in humidity (Myers 1985). Figure 6 also indicates a minimal decrease in summer concentrations from 2011 to 2012, which is partly a consequence of the $30 \mathrm{cfm}$ average intermittent ventilation that was selected and maintained by the initial researchers since 2010; a higher ventilation rate per ASHRAE 62.2 (60 to $75 \mathrm{cfm}$ ) would have accelerated material aging and the decline of $C_{i n}$.

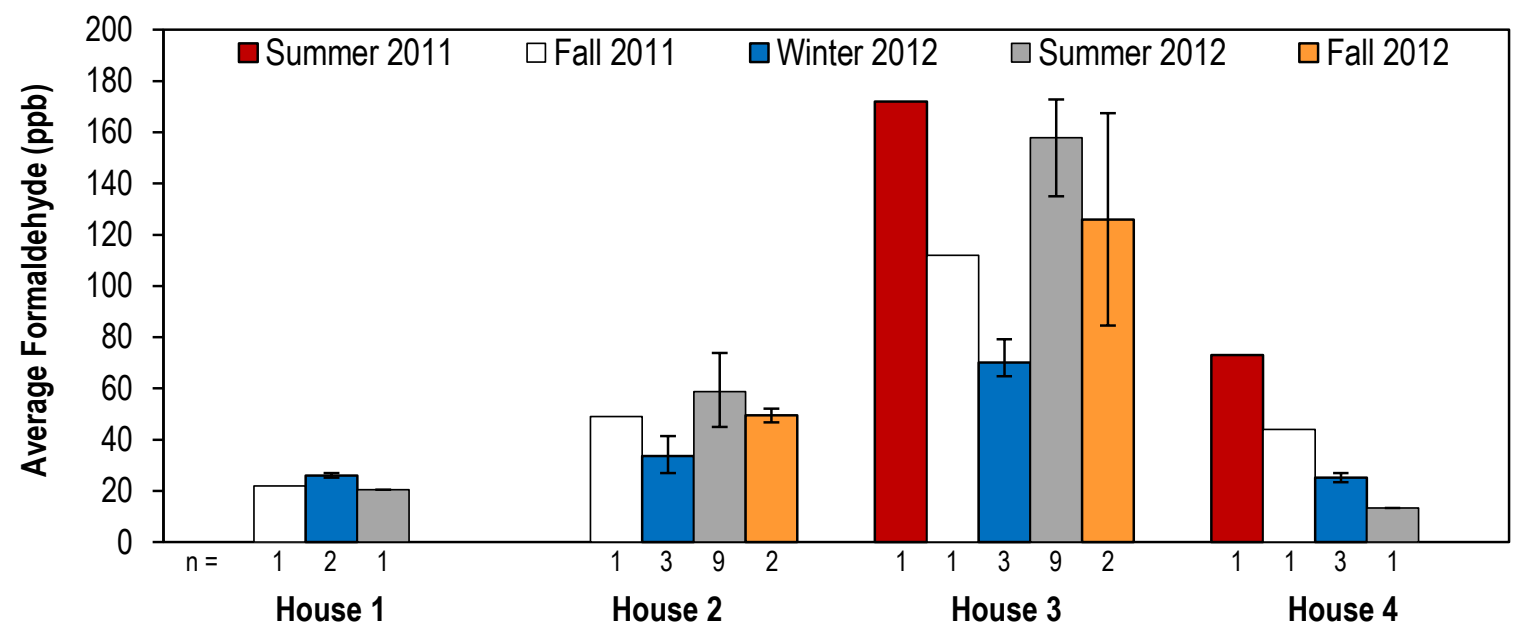

Figure 6. Seasonal formaldehyde concentrations (DNPH) from the four test houses.

a. Measurements are from 24-hr air samples.

b. Whiskers indicate minimum and maximum measured values.

c. Mechanical ventilation rates $\sim 30 \mathrm{cfm}$ (Houses 1 and $2=0.04 \mathrm{~h}^{-1}$, Houses 3 and $4=0.06 \mathrm{~h}^{-1}$ ) when the 2011 and winter 2012 data were gathered. Mechanical ventilation was shut down during the collection of the summer and fall 2012 data.

In order to identify potential major sources of formaldehyde, air samples were concurrently collected with DNPH cartridges from the living area, $1^{\text {st }}$ floor ceiling plenum, basement, vented attic, attached garage, crawlspace, and exterior wall cavities of each of the research homes. Measurements were obtained in March 2012 and were repeated to a lesser extent in July 2012; their respective results are shown in Figures 7A and 7B. Air samples that were gathered from locations inside the building envelope (i.e., living area, ${ }^{\text {st }}$ floor ceiling plenum and basement) had similar concentrations because the air handling unit helped mix the indoor air. Formaldehyde values from spaces adjacent to the living area (i.e., vented attic, attached garage and crawlspace) were lower than $C_{\text {in }}$ probably because these locations had relatively high 
ventilation rates or lower temperatures (e.g., sealed crawlspace in House 4). Measurements from the exterior wall cavities were collected by inserting an air sampler through a gap between the drywall and an electrical outlet. These concentrations were similar or higher than $C_{i n}$, which indicates that materials in the exterior wall cavities could have been important contributors to $C_{i n}$. Higher concentrations in the exterior wall cavities were probably encountered because air exchange rates between these spaces and outdoors were relatively low given the airtightness of the houses, and because of the high ratio of emitting surface area from sources, such as oriented strand board (OSB), to volume in these spaces. Just as with Figure 6, Figures 7A and 7B illustrate higher concentrations in the attached garage and exterior wall cavities during the summer than winter, which indicates the influence of outdoor temperature in these nonconditioned spaces.
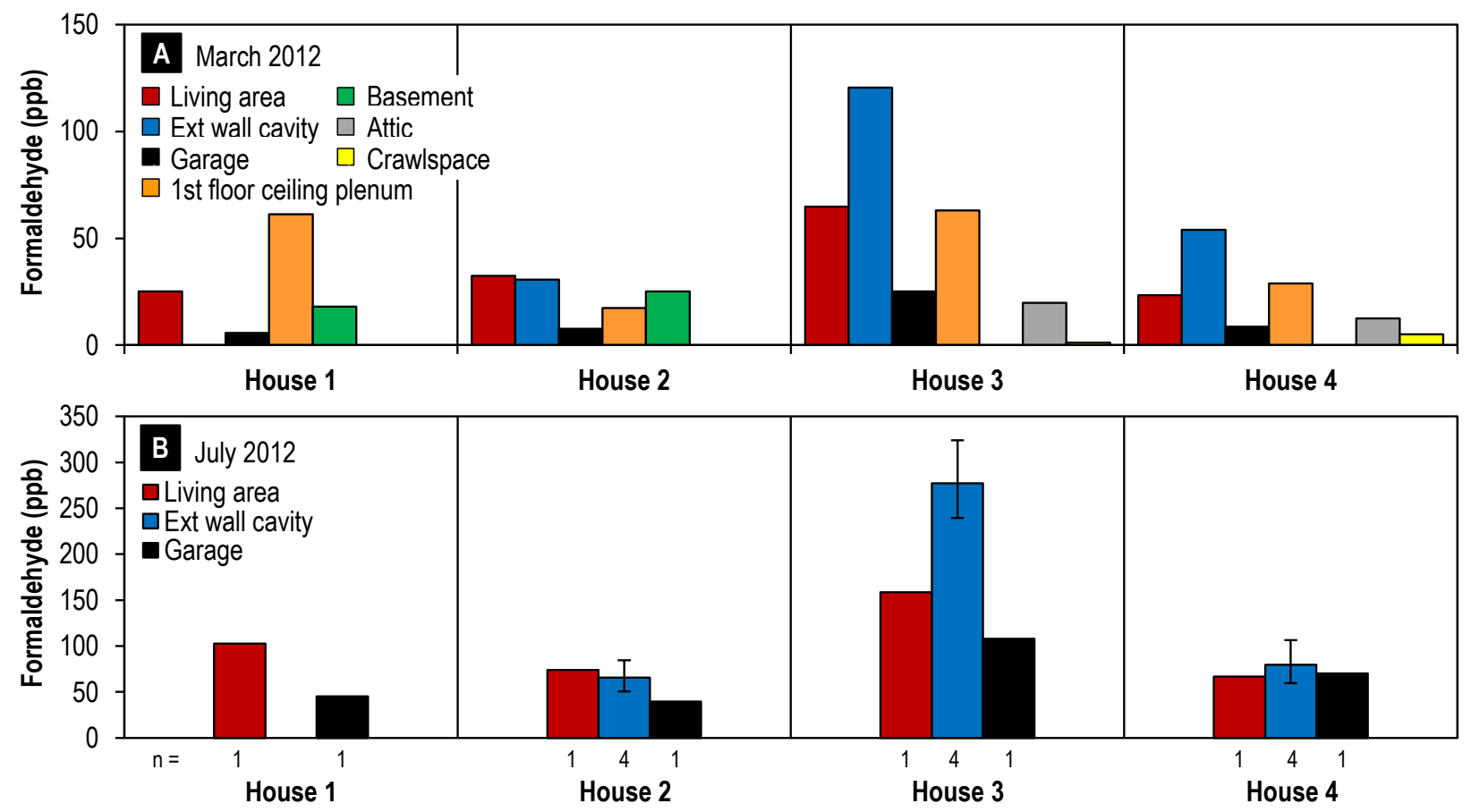

Figure 7. Formaldehyde concentrations (DNPH) collected in March and July 2012 from various locations within and adjacent to the living area.

a. Measurements are from 24-hr air samples.

b. Whiskers indicate minimum and maximum measured values.

c. Ventilation rates were less than $0.15 \mathrm{~h}^{-1}$ when these measurements were gathered.

Pressed-wood products (PWPs) used for framing (Kelly et al. 1999), cabinetry and passage doors (Hodgson et al. 2002) were likely the main source of formaldehyde in the test homes given that they were unfurnished and unoccupied. Measured formaldehyde concentrations would have been higher if furniture had been present given that they are commonly built with PWPs. These materials typically contain urea-formaldehyde resins that tend to have high and long-lasting formaldehyde emission rates. Pressed-wood products include particleboard, medium-density fiberboard (MDF) and engineered wood products such as OSB, plywood, and structural composite lumber (e.g., laminated strand lumber (LSL)). In the four test houses, PWPs were used as exterior sheathings in the walls and roof, and as the subfloor material. However, a major difference in the usage of PWPs was that House 3 had exterior double walls framed with $2 \times 4$ LSL studs at 24 " on center, while the other homes had regular sawn lumber as described in 
Appendix A; this difference increased the formaldehyde emitting surface area in the exterior walls cavities of House 3 by about $80 \%$. Moreover, the interior walls of House 3 were also framed with LSL studs. Unfortunately, material samples could not be collected from the homes to estimate their emission rates and confirm that LSL studs were responsible for the elevated formaldehyde concentrations in House 3. At the end of the study, an energy recovery ventilator (ERV) was installed in House 3 to expedite the depletion of indoor sources of formaldehyde through ventilation rates higher than ASHRAE's recommendations without producing elevated energy penalties and moisture levels.

\subsection{Formaldehyde Decay and Buildup}

Formaldehyde decay due to higher ventilation or filtration, and formaldehyde buildup after these were discontinued were evaluated because this information is necessary to develop strategies that can be used to optimize ventilation energy demands and exposure to air pollutants. These strategies include setback mechanical ventilation that matches occupancy schedules. To this end, we used Equation 3 to estimate formaldehyde concentrations during decay and buildup, and corroborated these theoretical values with the DNPH and Shinyei field data. Furthermore, we made the following assumptions with regard to initial and steady-state concentrations in Equation 3:

- Initial concentration before decay or buildup $\left(C_{i n, t=0}\right)$

○ DNPH: one or two-hour measurements that were collected immediately before decay or buildup started

- Shinyei: concentration that was monitored right before decay or buildup began

- Steady-state concentration $\left(C_{i n, s s}\right)$ after decay or buildup

○ DNPH: last 24-hr DNPH measurement gathered during decay or buildup

○ Shinyei: the average from the last 24 hours during decay or buildup

These evaluations were performed when both DNPH and Shinyei data were available so that their trends in formaldehyde concentration could be compared, and when variations in $T_{\text {in }}$ were minimal so that we could better isolate the effects from ventilation or filtration.

\subsubsection{Formaldehyde Buildup}

Using the aforementioned assumptions, formaldehyde buildup was examined after supply ventilation (tests T4-SV-H2 and T4-SV-H3) and filtration (tests T1-GF-H3, T1-GF-H4, T2-GFH3, T2-GF-H4, T7-GF-H2, and T7-GF-H3) were shut down in Houses 2, 3 and 4. The red and black dashed curves in the buildup part of Figures 2 to 5 show $C_{i n}$ estimates when sorption to storage materials was disregarded, i.e., the source time constant $(K L)$ in Equation 3 was set to zero. Most of the dashed curves in these Figures demonstrate that the omission of storage materials yields buildup rates that are slower than what was indicated by the DNPH and Shinyei data.

Storage materials or secondary sources of formaldehyde include drywall, carpet backing, and furnishings (Liu et al. 2009; Matthews et al. 1987; Sherman and Hult 2013). Given that the storage materials in the test houses were not easily identifiable, we estimated their combined source time constant by selecting a value for $K L$ that provided $C_{i n}$ values that closely matched 
both the DNPH and Shinyei data. $K L$ estimates were $0.15 \mathrm{~h}^{-1}$ in House 2, and $0.18 \mathrm{~h}^{-1}$ in Houses 3 and 4 as shown in Table 5. The red and black solid curves in Figures 2 to 5 illustrate how the $C_{\text {in }}$ predictions during buildup were improved by the inclusion of storage materials. To explain this effect, we derived Equation 4 as shown in Appendix B to estimate the amount of time it would take to reach $95 \%$ of the steady-state concentration $\left(t_{95 \%, \mathrm{ss}}\right)$ during buildup. Equation 4 suggests that when ventilation rates and $K L$ are comparable, as is the case in airtight homes, that sorption to storage materials has to be considered when assessing formaldehyde buildup. It is anticipated that sorption effects will be more important in fully furnished homes.

$$
t_{95 \%, S S}=\frac{-\ln \left(\frac{0.05}{1-\frac{C_{i n, t=0}}{C_{i n, S S}}}\right)}{\lambda+\frac{\eta Q_{f}}{V}+K L}
$$

Field measurements suggest that $C_{s s}$ was reached within 8 to 16 hours; similar values were obtained through Equation 4 as shown in Table 5.

Table 5. Ventilation rates, time constants $(K L)$ of storage materials, filtration system removal rate constants $\left(\eta Q_{f} / V\right)$, and time to reach $95 \%$ and $105 \%$ of steady-state concentrations.

\begin{tabular}{l} 
Test House \\
\cline { 3 - 9 }
\end{tabular}

\subsubsection{Formaldehyde Decay due to Supply Ventilation}

Just as in Section 3.5.1, the decay of formaldehyde due to supply ventilation was evaluated using Equation 3 and field measurements. Figures 4 and 5 show that setting $K L$ to $0.15 \mathrm{~h}^{-1}$ in House 2 and to $0.18 \mathrm{~h}^{-1}$ in House 3 did not have much of an effect on the decay profiles of tests T4-SVH2, T3-SV-H3 and T4-SV-H3. To better understand this, we derived Equation 5 as shown in Appendix B to estimate the amount of time it would take to reach a concentration $5 \%$ higher than steady-state during decay $\left(C_{105 \%, s s}\right)$. Equation 5 indicates that ventilation, sorption and filtration can similarly affect the rate of decay. However, ventilation overshadowed sorption given that 
the supply ventilation rates used during the tests were about two times higher than source time constant (i.e., $\mathrm{AER}=0.34$ to $0.48 \mathrm{~h}^{-1}$ vs. $K L=0.15$ to $0.18 \mathrm{~h}^{-1}$ ). In general, the influence from sorption to storage materials during formaldehyde decay is relevant in airtight homes with mechanical ventilation per ASHRAE 62.2, which ranges from 0.1 to $0.13 \mathrm{~h}^{-1}$ in the studied homes, but becomes less relevant at higher ventilation rates as was shown by the field data.

$$
t_{105 \%, S S}=\frac{-\ln \left(\frac{0.05}{\frac{C_{i n, t=0}}{C_{i n, s S}}-1}\right)}{\lambda+\frac{\eta Q_{f}}{V}+K L}
$$

DNPH and Shinyei data indicate that it took about 16 hours for $C_{i n}$ to reach steady-state after the ventilation was increased. As shown in Table 5, $t_{105 \%, \text { ss }}$ estimates ranged from 5.7 to 6.5 hours, which is in agreement with Figures 4B, 5A and 5B. Equation 3 appears to predict a faster decay than what was observed in the field, likely because it does not take into account all of the interactions formaldehyde experiences in a real setting.

\subsubsection{Formaldehyde Decay due to Gas-Phase Filtration}

The decay of formaldehyde due to filtration was assessed by estimating the removal rate constant $\left(\eta Q_{f} / V\right)$ of the filtration system and comparing its effectiveness against ventilation and sorption. The removal rate constant was calculated using two methods. In the first method, air was sampled upstream and downstream of the filtration system. This procedure was executed once and it yielded a single-pass removal efficiency $(\eta)$ of 0.85 and a removal rate constant of $0.72 \mathrm{~h}^{-1}$ in House 2, and $1.15 \mathrm{~h}^{-1}$ in Houses 3 and 4. Sidheswaran et al. (2011) obtained a similar singlepass removal efficiency $(\eta=0.8)$ from a particulate filter media with a manganese oxide-based catalyst coating that is currently under development. In the second method, $\eta Q_{f} / V$ was back calculated using Equation 3, $K L$ values from Section 3.5.1, measured flow rate through filtering device $\left(Q_{f}\right)$ of $750 \mathrm{cfm}$, and field data from Tests T2-GF-H3, T2-GF-H4, T7-GF-H2 and T7-GFH3. Measurements from Tests T1-GF-H3 and T1-GF-H4 were not utilized as part of this exercise because, as indicated in Figures $2 \mathrm{~A}$ and $3 \mathrm{~A}, T_{\text {in }}$ increased for about four hours before these tests and four hours into these experiments, which likely slowed the decay rate due to filtration. The removal rate constants that provided the best fit to both DNPH and Shinyei data were $0.21 \mathrm{~h}^{-1}$ in House 2, and $0.34 \mathrm{~h}^{-1}$ in Houses 3 and 4, which are equivalent to a filter removal efficiency of 0.21 . The fact that the whole-house method included the interactions that formaldehyde experiences in a realistic setting (e.g., continuous variations in emission rates due to changes in temperature and sorption to building materials) while the single-pass efficiency method did not may explain may explain why their results differed by a factor of four.

Figures 2 to 5 suggest that formaldehyde concentrations estimated through Equation 3 were minimally affected by the inclusion of the sorption effects because $K L$ values were 40 to $60 \%$ smaller than the sum of $\eta Q_{f} / V$ and AER. These figures also show that the concentrations predicted by Equation 3 were in good agreement with the field data. DNPH and Shinyei data indicate that 8 to 16 hours were needed for $C_{i n}$ to reach steady-state after filtration began. Values for $t_{105 \% \text {, ss }}$ ranged from 5.7 to 11.3 hours as indicated in Table 5. 


\subsection{Optimization}

In the present optimization efforts, we focused on the long term behavior of formaldehyde (i.e., monthly averages) due to environmental parameters.

\subsubsection{Multivariate Regressions}

We conducted multivariate regressions to evaluate the effect from various environmental parameters on formaldehyde concentrations. To this end, we used 24-hr DNPH data collected before each of the tests, and the steady-state 24-hr concentrations gathered during the supply ventilation tests. Indoor temperature and relative humidity measurements from various rooms were averaged; however, data from the basement in House 2 were not included in these calculations because they were significantly different than those from the rest of the house.

The models for Houses 2 and 3 revealed that $T_{i n}$ and AER dominated $C_{i n}$. Indoor relative humidity did not show a strong effect on $C_{i n}$ probably because most of the regression data were obtained during the summer and fall, which limited variations in $R H_{\text {in }}$. Furthermore, although increases in ventilation affected $R H_{i n}$, moisture effects on formaldehyde emissions from composite wood products can take days before they are noticeable. The derived equations for 24-hr average formaldehyde concentrations are:

$$
\begin{array}{ll}
C_{\text {in }, \text { House 2 }}=-90.4 A E R+9.43 T_{\text {in }}-2747 & \mathrm{R}^{2}=0.82 \\
C_{\text {in } \text { House } 3_{3}=-270 \mathrm{AER}+32.85 T_{\text {in }}-9556} & \mathrm{R}^{2}=0.93
\end{array}
$$

where the units for $C_{i n}$, AER and $T_{i n}$ are $\mathrm{ppb}, \mathrm{h}^{-1}$ and Kelvin, respectively. Figures 8A and 8B show good correlations between the formaldehyde estimates from these equations and the measured data. Equations 6 and 7 suggest that a $0.56^{\circ} \mathrm{C}\left(1^{\circ} \mathrm{F}\right)$ change in $T_{\text {in }}$ could lead to variations in $C_{\text {in }}$ of $5.2 \mathrm{ppb}$ and $18 \mathrm{ppb}$ in Houses 2 and 3, respectively. Similarly, changes in AER of $0.05 \mathrm{~h}^{-1}$ could cause $C_{\text {in }}$ to vary $4.5 \mathrm{ppb}$ in House 2 and $14 \mathrm{ppb}$ in House 3 . These results should be used with caution because the derivation of Equations 6 and 7 did not take into account source aging, and because most of the data (82\% in House 2 and $73 \%$ in House 3) that were used to generate the regression were collected during the summer. Additionally, given that these equations were derived from unoccupied homes, they do not necessarily apply to occupied houses because they do not take into consideration furnishings or occupant behavior. 

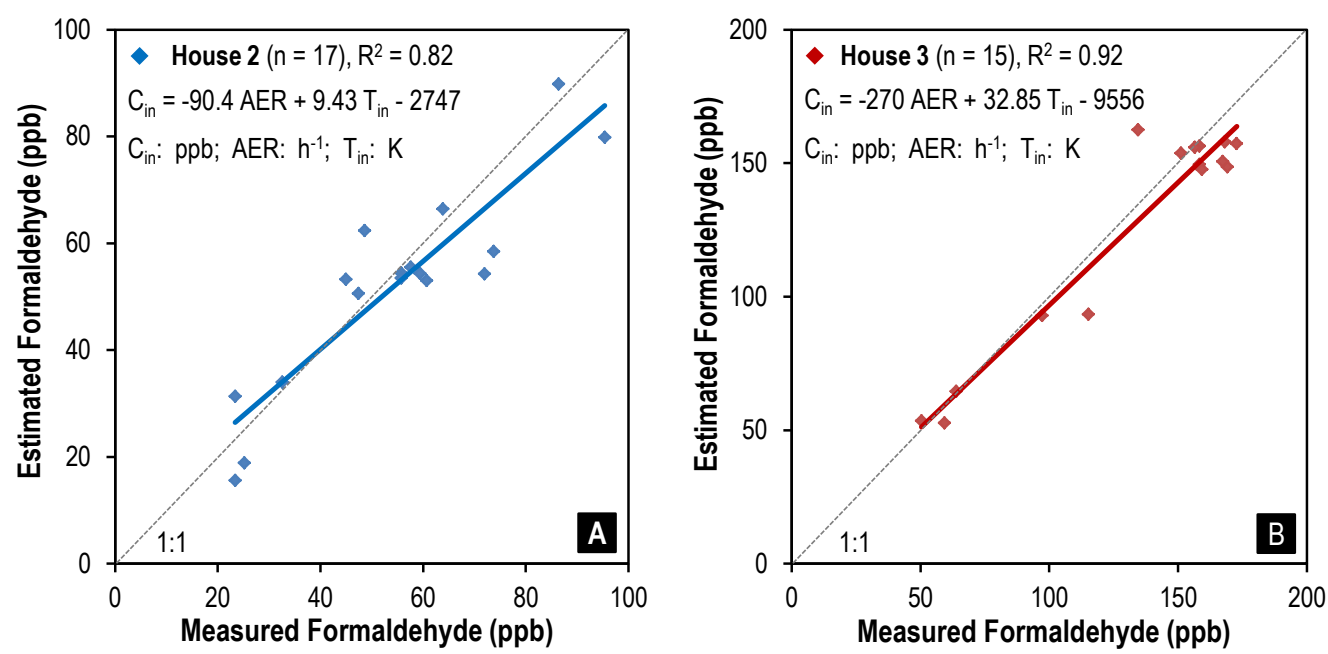

Figure 8. Measured and estimated 24-hour average formaldehyde concentrations from multivariate regression models.

\subsubsection{EnergyPlus Models}

EnergyPlus models generated for Houses 2 and 3 were coupled with Equations 6 and 7 to predict energy loads and cost, and formaldehyde concentrations. Major assumptions include:

a. Well-mixed environment

b. Regression equations that were derived with 24-hr average $C_{i n}$ and $T_{\text {in }}$ can be used to estimate 1-hr formaldehyde emission rates and concentrations

c. $C_{\text {out }}=2 \mathrm{ppb}$

d. No formaldehyde sinks

e. Baseline $T_{\text {in }}$ setpoints per the Building America protocol (Hendron and Engebrecht, 2010)

Heating setpoint $=21.7^{\circ} \mathrm{C}\left(71^{\circ} \mathrm{F}\right)$

Cooling setpoint $=24.4^{\circ} \mathrm{C}\left(76^{\circ} \mathrm{F}\right)$

f. Filtration system:

$\eta=0.21$

$Q_{f}=638 \mathrm{~m}^{3} / \mathrm{h}(375 \mathrm{cfm})$

Energy use $=0.32 \mathrm{~W} / \mathrm{m}^{3} / \mathrm{h} \times 638 \mathrm{~m}^{3} / \mathrm{h}=203 \mathrm{~W}$

\subsubsection{EnergyPlus Cases}

Table 6 describes the four cases that were investigated with the EnergyPlus models. Case 1 represents the baseline, where mechanical ventilation rates were set per ASHRAE 62.2-2010 and the Building America protocol was utilized for $T_{i n}$. We varied parameters in the remaining cases with the goal of finding the most energy efficient and economical means to reduce the formaldehyde concentrations that we estimated in Case 1. In Case 2 we examined the effect of lowering the cooling setpoint by $1.1^{\circ} \mathrm{C}\left(2^{\circ} \mathrm{F}\right)$, while in Case 3 we focused on ventilation rates that are twice the ASHRAE requirements. Case 4 evaluated the effects from gas-phase filtration and a 50\% decrease to the ASHRAE ventilation rates. In all of these simulations we used the 2012 weather data that we collected at the test site, and we assumed the electricity cost to be $\$ 0.10 / \mathrm{KWh}$. 
Table 6. Cases simulated with EnergyPlus.

\begin{tabular}{|c|c|c|c|}
\hline Case & Mechanical Ventilation $\left(\mathrm{cfm}, \mathrm{h}^{-1}\right)$ & Indoor Temperature $\left({ }^{\circ} \mathrm{C},{ }^{\circ} \mathrm{F}\right)$ & Gas-Phase Filtration \\
\hline 1 & ASHRAE 62.2: & Building America protocol: & \\
\hline \multirow[t]{2}{*}{ (Baseline) } & House $2=75,0.1$ & Heating setpoint $=21.7,71$ & - \\
\hline & House $3=60,0.13$ & Cooling setpoint $=24.4,76$ & \\
\hline \multirow[t]{3}{*}{2} & ASHRAE 62.2: & Heating setpoint $=21.7,71$ & \\
\hline & House $2=75,0.1$ & Cooling setpoint $=\underline{23.3,74}$ & \\
\hline & House $3=60,0.13$ & & \\
\hline \multirow[t]{3}{*}{3} & $\underline{\mathbf{2}} \times$ ASHRAE 62.2 & Building America protocol: & \\
\hline & House $2=150,0.2$ & Heating setpoint $=21.7,71$ & \\
\hline & House $3=\underline{120,0.26}$ & Cooling setpoint $=24.4,76$ & \\
\hline \multirow[t]{3}{*}{4} & $\underline{0.5} \times$ ASHRAE $62.2:$ & Building America protocol: & House 2: $\eta Q_{f} / V=0.11 \mathrm{~h}^{-1}$ \\
\hline & $\overline{\text { House } 2}=\underline{38,0.05}$ & Heating setpoint $=21.7,71$ & House 3: $\eta Q_{f} / V=0.17 \mathrm{~h}^{-1}$ \\
\hline & House $3=\underline{30,0.07}$ & Cooling setpoint $=24.4,76$ & \\
\hline
\end{tabular}

Figures 9 and 10 summarize the monthly and annual results obtained from House 2 and House 3 EnergyPlus models, respectively. In general, HVAC loads and energy costs were higher during the winter season, followed by the summer months, due to larger indoor to outdoor temperature differentials. Additionally, formaldehyde concentrations were greater during the warmer months and these lessened with seasonal changes such as decreases in indoor temperatures and increases in infiltration due to larger indoor to outdoor temperature differentials. In the baseline case, summer concentrations exceeded winter values by a factor of two in House 2 (July $=51 \mathrm{ppb}$, January $=24 \mathrm{ppb}$ ) and a factor of four in House 3 (July $=168 \mathrm{ppb}$, January $=38 \mathrm{ppb})$. The more specific results that follow were highly influenced by the fact that the test Houses are airtight, well insulated as described in Appendix A, have very efficient HVAC units (i.e., House 2: heating/cooling COPs of 4.1 and 5.0, respectively; House 3: heating/cooling COPs of 3.6 and 4.2, respectively, and Building America's COP baseline is 3.1), and are located in a relatively mixed-humid climate. Also, the results from House 2 and House 3 should not be compared to each other because of their differences in size, construction, HVAC units, and ASHRAE ventilation requirements (House $2=75 \mathrm{cfm}, 0.10 \mathrm{~h}^{-1}$; House $3=60 \mathrm{cfm}, 0.13 \mathrm{~h}^{-1}$ ).

On an annual basis, the four evaluated cases resulted in distinct findings. In House 2, higher ventilation and gas-phase filtration decreased the annual average formaldehyde concentration from $36 \mathrm{ppb}$ (baseline case) to about $27 \mathrm{ppb}$, at a cost of \$140/year and \$115/year, respectively. The annual average concentration was higher in Case 2, $32 \mathrm{ppb}$, because changing the cooling setpoint is only applicable during the cooling season; consequently, the electricity cost penalty was $\$ 40 /$ year. With regard to House 3, the annual baseline concentration was decreased from $102 \mathrm{ppb}$ to $88 \mathrm{ppb}$ in Case 2, $77 \mathrm{ppb}$ in Case 3, and $66 \mathrm{ppb}$ in Case 4. Their respective increases in cost were $\$ 35, \$ 80$ and $\$ 150$ per year. Results from House 2 and House 3 also indicate that cutting the ventilation rates by $50 \%$ of what is required by ASHRAE lowered annual energy penalties in Houses 2 and 3 by 8.6 MBtu (\$60/year) and 3.4 MBtu (\$30/year), respectively. These findings suggest that in high-performance houses (i.e., airtight envelope, good insulation and efficient HVAC unit(s)) located in relatively mix-humid climate, aiming for lower than the ASHRAE ventilation rates provides minimal energy benefits that would be easily canceled out by the energy use of a filtration system as shown in Figures 9B and 10B. 

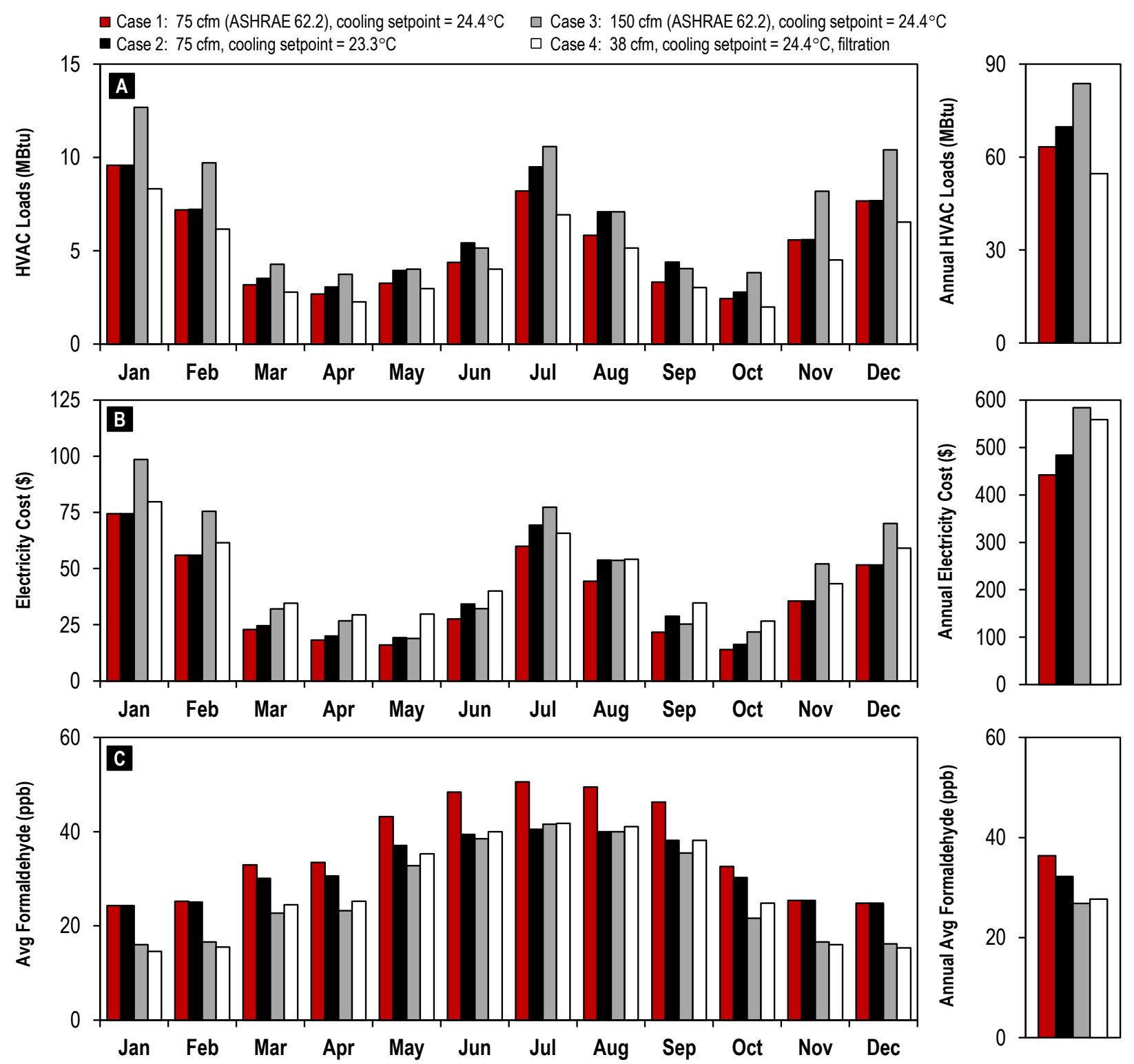

Figure 9. EnergyPlus estimates for House 2. A: HVAC latent and sensible loads. B: Electricity costs due to HVAC and filtration systems. C: Formaldehyde concentrations. 

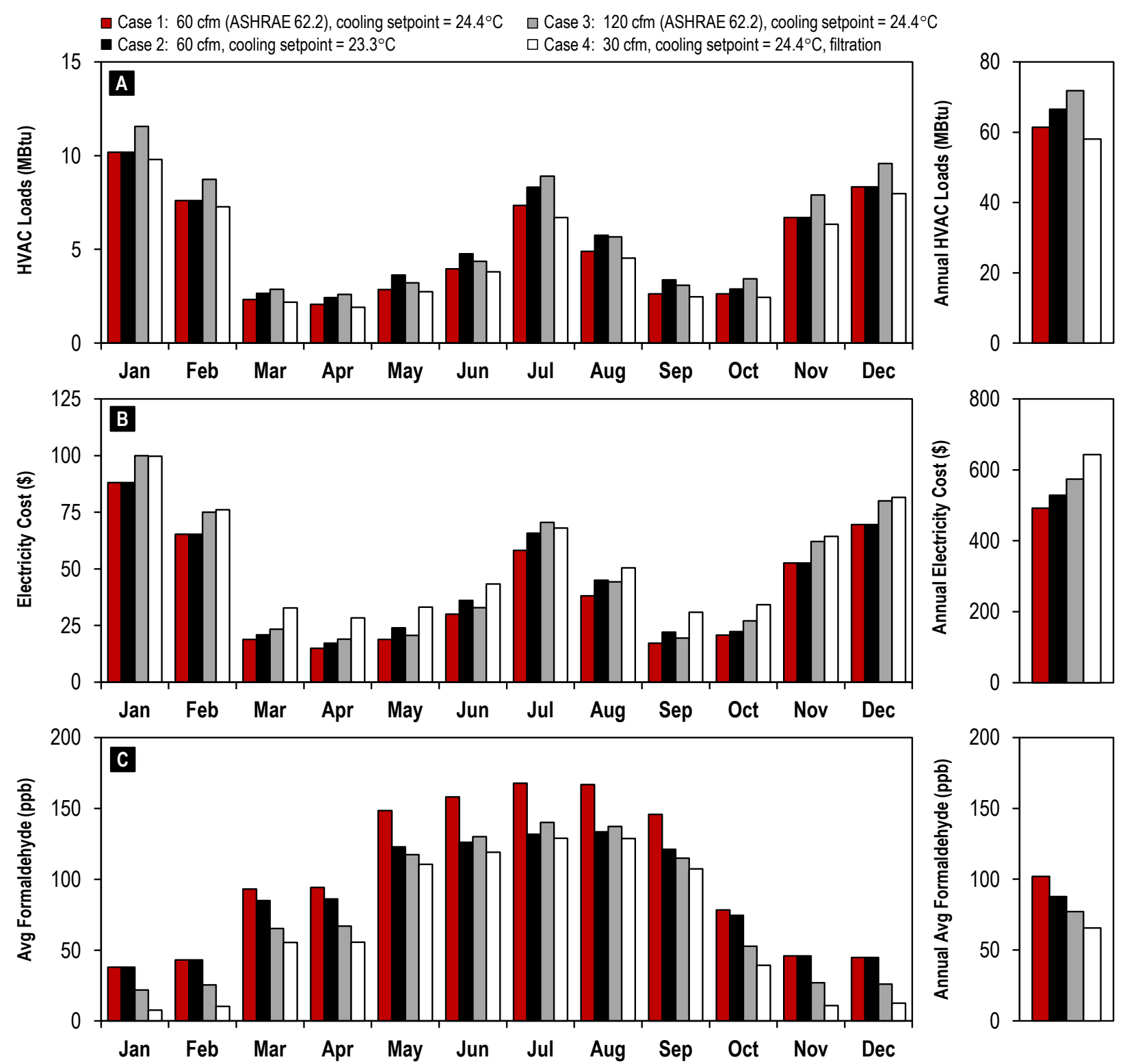

Figure 10. EnergyPlus estimates for House 3. A: HVAC latent and sensible loads. B: Electricity costs due to HVAC and filtration systems. C: Formaldehyde concentrations. 
The three explored strategies were similarly successful in decreasing formaldehyde concentrations from May to September, which are the months when concentrations were the highest. In Case 1, monthly average $C_{i n}$ ranged from 43 to $51 \mathrm{ppb}$ in House 2, and from 146 to $168 \mathrm{ppb}$ in House 3. Cases 2, 3 and 4 decreased these concentrations by about $20 \%$ in both homes. These reductions in $C_{i n}$ caused increases in energy cost ranging from $\$ 5$ to $\$ 10 /$ month due to a lower cooling setpoint, $\$ 2$ to $\$ 17 /$ month due to higher ventilation rates, and $\$ 5$ to $\$ 15 /$ month due to gas-phase filtration. The ranges in cost are explained by the broad span of outdoor temperatures observed from May to September.

During the cooler months (i.e., November through February), filtration was more effective on an energy basis than higher ventilation rates. In the baseline case, House 2 had monthly average concentrations of $25 \mathrm{ppb}$, which were decreased by about $10 \mathrm{ppb}$ due to filtration at a rate of $\$ 7 /$ month, and $9 \mathrm{ppb}$ due to increased ventilation at a cost $\$ 20 /$ month. Energy penalties from the latter were due to higher indoor to outdoor temperature differentials during the heating season. In House 3, the baseline case presented monthly average $C_{i n}$ values of $44 \mathrm{ppb}$, which filtration and higher ventilation decreased by about $33 \mathrm{ppb}$ and $18 \mathrm{ppb}$, respectively. The electricity cost from these two strategies was similar at about $\$ 11$ /month. Ventilation expenses were lower in House 3 given that it has a smaller volume and lower ASHRAE ventilation requirement than House 2. Case 2 was not included in this analysis because altering the cooling setpoint is not applicable to the heating season.

Higher ventilation and filtration produced somewhat comparable results during the shoulder months of March, April and October. In House 2, the baseline case resulted in a monthly average $C_{\text {in }}$ of $33 \mathrm{ppb}$, which was reduced by $10 \mathrm{ppb}$ through higher ventilation and $8 \mathrm{ppb}$ due to filtration, at a cost of $\$ 9 /$ month and $\$ 12 /$ month, respectively. In House 3, twice as much fresh air decreased $C_{i n}$ by $27 \mathrm{ppb}$ at a cost of $\$ 5 /$ month, and reductions due to filtration were $38 \mathrm{ppb}$ that led to electricity increases of $\$ 14 /$ month. Energy penalties from higher ventilation during the shoulder months were not as severe as during the winter and summer because of milder outdoor temperatures.

Each of the investigated strategies poses advantages and disadvantages. Lowering the cooling setpoint causes no capital cost, focuses on the months when formaldehyde emissions are the highest, and lowers indoor relative humidity during the summer when these tend to be the highest. A major drawback of this strategy is that it would increase energy demand during the time of the day when utilities experience their peak loads. Increasing mechanical ventilation rates will help with the reduction of emissions from long-term sources of pollutants. This strategy will not require significant additional capital cost in airtight homes other than installing a larger outdoor air intake duct than what is required to meet ASHRAE's minimum ventilation rates. Disadvantages from higher ventilation include that it will increase latent loads in the summer, which could be difficult to manage by HVAC units without a dedicated dehumidification system. Furthermore, its energy penalties during the winter are significantly high, but it could be argued that increased ventilation is not needed during the heating season because of lower indoor concentrations and greater infiltration. In addition to decreasing formaldehyde concentrations, the gas-phase filtration system also lessens VOC concentrations. Moreover, by allowing lower ventilation rates, the filtration system reduces indoor concentrations of pollutants that are generated outdoors, and decreases indoor moisture levels 
during the summer given that outdoor sources are dominant during this period. However, this system requires an initial capital cost of $\$ 2800$, the price to replace the carbon canister is on the order of $\$ 625$ per year, and the system consumes $200 \mathrm{~W}$ or about $\$ 180$ per year.

\subsection{Conclusions}

Formaldehyde remains a pollutant of concern in new homes. Concentrations from four highperformance test houses (i.e., airtight, good insulation, and efficient HVAC unit(s)), that were unfurnished and unoccupied, showed seasonal variations of $22 \mathrm{ppb}$ to $173 \mathrm{ppb}$. Likely formaldehyde sources include pressed-wood products used to frame houses, cabinetry and passage doors. The persistence of indoor formaldehyde concentrations was likely reinforced by storage materials that continuously adsorb and desorb this air contaminant. Concentrations were higher during the summer months primarily because emission rates from sources rise with increases in temperature, and to a lesser extent because natural ventilation decreases with lower indoor to outdoor temperature differentials. Supply ventilation and gas-phase filtration were effective means to reduce indoor formaldehyde concentrations; however, exhaust ventilation had minimal influence on this pollutant.

Results from simulations suggest that formaldehyde concentrations obtained while ventilating per ASHRAE 62.2 could be decreased by about $20 \%$ from May through September through three strategies: 1) increasing ASHRAE mechanical ventilation by a factor of two, 2) reducing the thermostat setpoint from $24.4^{\circ} \mathrm{C}\left(76^{\circ} \mathrm{F}\right)$ to $23.3^{\circ} \mathrm{C}\left(74^{\circ} \mathrm{F}\right)$, or 3$)$ running a gas-phase filtration system while decreasing mechanical ventilation per ASHRAE by half. In the mixed-humid climate of Oak Ridge, TN, these strategies caused minimal to modest increases in electricity cost of $\sim \$ 5$ to $\sim \$ 15 /$ month depending on the outdoor conditions. A deeper understanding of the interactions of formaldehyde in houses (e.g., adsorption to and desorption from storage materials) could help further optimize energy consumption and human exposure to formaldehyde in homes.

\section{Acknowledgements}

This work was supported by the Assistant Secretary for Energy Efficiency and Renewable Energy, Office of the Building Technology Program, U.S. Department of Energy, under Contract No. DE-AC05-00OR22725.

We would like to thank Richard Corsi, Brett Singer, Brent Stephens, Ellison Carter and Carl Bero for their input. Additionally, we would like to thank Americair Corporation and Lennox Industries for equipment donations, and Matrix Analytical Laboratories, Inc., for their assistance with sample analysis. 


\section{References}

Adgate JL, Church TR, Ryan AD, Ramachandran G, Fredrickson AL, Stock TH, et al. 2004. Outdoor, indoor, and personal exposure to VOCs in children. Environ Health Perspect 112:1386-1392.

Ally MR, Munk JD, Baxter VD. 2011. Field test of high efficiency residential buildings with ground-source and air-source heat pump systems. In: Proceedings from the $10^{\text {th }}$ IEA Heat Pump Conference, 27 June - 31 August 2011, Tokyo, Japan.

ASHRAE. 2010. Standard 62.2-2010. Ventilation and acceptable indoor air quality in low-rise residential buildings. Atlanta, GA: American Society of Heating, Refrigerating and AirConditioning Engineers.

Boudreaux PR, Hendrick T, Christian J, Jackson RK. 2012. Deep residential retrofits in East Tennessee. Oak Ridge National Laboratory. Report ORNL/TM-2012/109.

Clayton CA, Pellizzari ED, Whitmore RW, Perritt RL, Quackenboss JJ. 1999. National Human Exposure Assessment Survey (NHEXAS): distributions and associations of lead, arsenic and volatile organic compounds in EPA Region 5. J Expo Anal Environ Epidemiol 9(5):381-392.

EPA (Environmental Protection Agency). 1999. Compendium Method TO-11a: Determination of formaldehyde in ambient air using adsorbent cartridge followed by high performance liquid chromatography (HPLC). $2^{\text {nd }} \mathrm{ed}$.

EPA (Environmental Protection Agency). 1999. Compendium Method TO-17: Determination of volatile organic compounds in ambient air using active sampling onto sorbent tubes. $2^{\text {nd }}$ ed.

Fisk WJ, Faulkner D, Palonen J, Seppanen O. 2002. Performance and costs of particle air filtration technologies. Indoor Air 12:223-234.

Hawthorne AR, Gammage RB, Dudney CS. 1986. An indoor air quality study of 40 East Tennessee homes. Environ Int 12:221-239.

Huang J, Hanford J, Yang F. 1999. Residential heating and cooling loads component analysis. Lawrence Berkeley National Laboratory. Report LBL-44636.

Hodgson AT, Beal D, McIlvaine JER. 2002. Sources of formaldehyde, other aldehydes and terpenes in a new manufactured house. Indoor Air 12:235-242.

Hun DE, Siegel JA, Morandi MT, Stock TH, Corsi RL. 2009. Cancer risk disparities between Hispanic and non-Hispanic White populations: the role of exposure to indoor air pollution. Environ Health Perspect 117:1925-1931.

IECC. 2012. 2012 International Energy Conservation Code. Country Club Hill, IL: International Code Council. 
Hendron R, Engebrecht C. 2010. Building America house simulation protocols. National Renewable Energy Laboratory. Report TP-550-49426.

Kelly TJ, Smith DL, Satola J. 1999. Emission rates of formaldehyde from materials and consumer products found in California homes. Environ Sci Technol 22:81-88.

Klepeis NE, Nelson WC, Ott WR, Robinson JP, Tsang AM, et al. 2001. The National Human Activity Pattern Survey (NHAPS): a resource for assessing exposure to environmental pollutants. J Expo Anal Environ Epidemiol 11:231-252.

OEHAA (Office of Environmental and Health Hazard Assessment). 2012. OEHHA Acute, 8hour and chronic reference exposure levels (REL). Available: http://oehha.ca.gov/air/allrels.html [accessed 15 May 2012].

Matthews TG, Hawthorne AR, Thompson CV. 1987. Formaldehyde sorption and desorption characteristics of gypsum wallboard. Environ Sci Technol 21(7): 629-634.

Matthews T, Reed T, Daffron C, Hawthorne A. 1984. Environmental dependence of formaldehyde emissions from pressed-wood products: experimental studies and modeling. In: Eighteenth Washington State University International Particleboard/Composite Materials Series Symposium, 41-70, Pullman, WA,

Meyer B, Hermanns K. 1985. Diurnal variations of formaldehyde exposure in mobile homes. J Environ Health 48(2):57-61.

Miller WA, Kośny J, Shrestha S, Christian J, Karagiozis A, et al. 2010. Advanced residential envelopes for two pair of energy-saver homes. In: Proceedings from the ACEEE Summer Study on Energy Efficiency in Buildings, 15-20 August 2010, Pacific Grove, CA.

Mortensen DK, Walker IS, Sherman MH. 2011. Optimization of occupancy based demand controlled ventilation in residences. Int J Ventilation 20:1473-2215.

Myers GE. 1983. Formaldehyde emission from particleboard and plywood paneling:

measurement, mechanism, and product standards. Forest Prod J 33:27-37.

Myers GE. 1984. Effect of ventilation rate and board loading on formaldehyde concentration: a critical review of the literature. Forest Prod J 34:59-68.

Myers GE. 1985. The effects of temperature and humidity on formaldehyde emission from UFbonded boards: a literature critique. Forest Prod J 35:20-31.

Liu X, Mason M, Guo Z, Krebs K, Roache N. 2009. Gypsum wallboard as a sink for formaldehyde. In: Proceedings from the $9^{\text {th }}$ International Healthy Buildings Conference. 13-17 September 2009, Syracuse, NY. 
Offerman FJ. 2009. Ventilation and indoor air quality in new homes. California Air Resources Board and California Energy Commission, PIER Energy-Related Environmental Research Program. Collaborative Report. CEC-500-2009-085.

Rudd A, Bergey D. 2013. Ventilation system effectiveness and tested indoor air quality impacts. Building Science Corporation, RR-1309, prepared for the National Renewable Energy Laboratory.

Sekine Y, Nishimur A. 2001. Removal of formaldehyde from indoor air by passive type aircleaning materials. Atmos Environ 35:2001-2007.

Sidheswaran MA, Destaillats H, Sullivan DP, Larsen J, Fisk WJ. 2011. Quantitative roomtemperature mineralization of airborne formaldehyde using manganese oxide catalysts. Applied Catalysis B: Environ 107:34-41.

Sherman MH, Hult EL. 2013. Impacts of contaminant storage on indoor air quality: Model development. Atmos Environ 72:41-49.

Willem H, Hult EL, Hotchi T, Russel ML, Maddalena RL, Singer BC. 2013. Ventilation control of volatile organic compounds in new US homes: Results of a controlled field study in nine residential units. Lawrence Berkeley National Laboratory. Report LBNL-6022E. 


\section{Appendix A: Description of the ZEBRAlliance Houses}

Table A1. ZEBRA houses footprint areas and volumes.

\begin{tabular}{|c|c|c|c|c|c|}
\hline \multirow{2}{*}{ Houses } & \multicolumn{4}{|c|}{ Footprint Area $\left(\mathrm{m}^{2}\right)$} & \multirow{2}{*}{ Volume $\left(\mathrm{m}^{3}\right)$} \\
\hline & Basement & $1^{\text {st }}$ Floor & $2^{\text {nd }}$ Floor & Total & \\
\hline 1 and 2 & 141 & 141 & 63 & 345 & 1280 \\
\hline 3 and 4 & - & 167 & 85 & 252 & 805 \\
\hline
\end{tabular}


Table A2. ZEBRA houses envelope description.

\begin{tabular}{|c|c|c|c|c|}
\hline Component & House 1 & House 2 & House 3 & House 4 \\
\hline \multicolumn{5}{|l|}{ Foundation } \\
\hline Interior insulation & - & - & - & $\begin{array}{l}\text { R-9.8: } 1-1 / 2 \text { " foil-faced } \\
\text { polyisocyanurate }\end{array}$ \\
\hline Framing & $12 "$ concrete walls & $12 "$ concrete walls & 8" CMU & 8" CMU \\
\hline Exterior insulation & $2-3 / 8$ " rigid fiberglass & $2-3 / 8$ " rigid fiberglass & - & - \\
\hline Waterproofing & $\begin{array}{l}\text { Liquid-applied } \\
\text { membrane }\end{array}$ & $\begin{array}{l}\text { Liquid-applied } \\
\text { membrane }\end{array}$ & $\begin{array}{l}\text { Liquid-applied } \\
\text { membrane }\end{array}$ & $\begin{array}{l}\text { Liquid-applied } \\
\text { membrane }\end{array}$ \\
\hline Above grade cladding & Stone & Stone & Stone & Stone \\
\hline \multicolumn{5}{|l|}{ Wall } \\
\hline Interior sheathing & Gypsum board & Gypsum board & Gypsum board & $\begin{array}{c}\text { Gypsum board w/ low-e } \\
\text { foil facing }\end{array}$ \\
\hline Framing & 6-1/2" SIPs & $2 \times 6$ studs at $24 "$ o.c. & $\begin{array}{l}\text { Double wall: staggered } \\
2 \times 4 \text { LSL studs at } 24 \text { " oc }\end{array}$ & EIFS \\
\hline $\begin{array}{l}\text { Insulation } \\
\left(\mathrm{h} \cdot \mathrm{ft}^{2} \cdot{ }^{\circ} \mathrm{F} / \mathrm{Btu}\right)\end{array}$ & R-21: 5-5/8" EPS foam & $\begin{array}{c}\text { R-21: R-19 fiberglass } \\
\text { batt and } 1 / 2 " \text { closed-cell } \\
\text { foam (R-3) }\end{array}$ & $\begin{array}{c}\text { R-30: blown-in } \\
\text { cellulose w/ } 20 \% \text { PCM } \\
\text { by weight in exterior } \\
\text { wall cavity }\end{array}$ & R-20: 5" EPS foam \\
\hline Exterior sheathing & OSB & OSB & OSB & Plywood \\
\hline $\begin{array}{l}\text { Weather resistive } \\
\text { barrier }\end{array}$ & SIPs w/ DrainWrap TM & $\begin{array}{l}\text { Barritech VP liquid- } \\
\text { applied membrane }\end{array}$ & $\begin{array}{c}\text { ZIP system w/ Delta- } \\
\text { Dry }^{\circledR}\end{array}$ & $\begin{array}{l}\text { Liquid-applied } \\
\text { membrane }\end{array}$ \\
\hline Cladding & $\begin{array}{l}\text { Fiber cement siding and } \\
\text { stacked stone }\end{array}$ & $\begin{array}{l}\text { Fiber cement siding and } \\
\text { stacked stone }\end{array}$ & $\begin{array}{l}\text { Fiber cement siding and } \\
\text { stacked stone }\end{array}$ & $\begin{array}{l}\text { Acrylic stucco and } \\
\text { stacked stone }\end{array}$ \\
\hline Paint & CoolWall $^{\circledR}$ & CoolWall $^{\circledR}$ & ColorPlus $^{\circledR}$ & Colored texture finish \\
\hline \multicolumn{5}{|l|}{ Windows } \\
\hline Triple pane windows & Pella & Pella & ALSIDE & Serious Materials \\
\hline Roof & \multicolumn{2}{|c|}{ Cathedral ceiling } & \multicolumn{2}{|c|}{ Conventional attic } \\
\hline Framing & $10-1 / 4 "$ SIPs & $2 \times 10$ rafters at $24 "$ oc & Trusses at $24 "$ oc & Trusses at 24" oc \\
\hline $\begin{array}{l}\text { Attic floor insulation } \\
\left(\mathrm{h} \cdot \mathrm{ft} \cdot{ }^{\circ} \mathrm{O} / \mathrm{Btu}\right)\end{array}$ & - & - & $\begin{array}{c}\text { R-50: blown-in } \\
\text { cellulose w/ } 20 \% \text { PCM } \\
\text { by weight }\end{array}$ & $\begin{array}{l}\text { R-50: blown-in } \\
\text { fiberglass }\end{array}$ \\
\hline Attic ventilation & - & - & $\begin{array}{l}\text { Soffit and ridge vents, } \\
\text { and solar fans }\end{array}$ & $\begin{array}{l}\text { Soffit and ridge vents, } \\
\text { and solar fans }\end{array}$ \\
\hline $\begin{array}{l}\text { Rood deck insulation } \\
\left(\mathrm{h} \cdot \mathrm{ft}^{2} \cdot{ }^{\circ} \mathrm{F} / \mathrm{Btu}\right)\end{array}$ & R-35: 9-3/8" EPS & $\begin{array}{l}\text { R-50: foil faced, aged } \\
\text { phenolic boards }\end{array}$ & - & - \\
\hline Sheathing & OSB & OSB & $\begin{array}{l}\text { OSB w/ LP TechShield } \\
\text { Radiant Barrier }\end{array}$ & $\begin{array}{l}\text { OSB w/ LP TechShield } \\
\text { Radiant Barrier }\end{array}$ \\
\hline Underlayment & DELTA ${ }^{\circledR}$-TRELA & Felt paper & SharkSkin & SharkSkin \\
\hline Roof deck ventilation & Soffit and ridge vents & Soffit and ridge vents & - & Above sheathing \\
\hline Cladding & $\begin{array}{l}\text { IRR standing seam } \\
\text { metal }\end{array}$ & $\begin{array}{l}\text { IRR standing seam } \\
\text { metal }\end{array}$ & $\begin{array}{l}\text { IRR standing seam } \\
\text { metal w/ EPS foam } \\
\text { insert }\end{array}$ & IRR asphalt shingle \\
\hline
\end{tabular}


Table A3. ZEBRA houses HVAC system and hot water heater descriptions.

\begin{tabular}{|c|c|c|c|c|}
\hline System & House 1 & House 2 & House 3 & House 4 \\
\hline \multicolumn{5}{|l|}{ HVAC } \\
\hline Type & WAHP & WAHP & WAHP & ASHP \\
\hline Capacity (tons) & 2 & 2 & 2 & 2 (dual) \\
\hline Blower & Variable speed & Variable speed & Variable speed & Variable speed \\
\hline Rated Cooling COPa & 5.4 & 5.4 & 5.4 & - \\
\hline Actual average COPa & 5.0 & 5.0 & 4.2 & 5.0 \\
\hline Heating COPb & 4 & 4 & 4 & - \\
\hline Actual average $\mathrm{COPb}^{\mathrm{b}}$ & 3.9 & 4.1 & 3.6 & 3.2 \\
\hline Loop layout & Horizontal & Horizontal & Vertical well & - \\
\hline Loop length (ft) & 1815 & 2610 & 310 & - \\
\hline SEERc & - & - & - & 18.4 \\
\hline $\mathrm{HSPF}^{\mathrm{d}}$ & - & - & - & 9.1 \\
\hline Refrigerant & R410A & R410A & R410A & R410A \\
\hline \multicolumn{5}{|l|}{ Mechanical ventilation } \\
\hline Type & ERV & ERV & AirCycler & AirCycler \\
\hline ERV total recovery efficiency (\%)e & 52 & 52 & - & - \\
\hline ERV apparent sensible effectiveness $(\%)^{\dagger}$ & 75 & 75 & - & - \\
\hline \multicolumn{5}{|l|}{ Hot water heater } \\
\hline Type & WWHP & WWHP & WWHP & HPWH \\
\hline Capacity (ton) & $1 \frac{1 / 2}{2}$ & $1 \frac{1 / 2}{2}$ & $1 \frac{1 / 2}{2}$ & - \\
\hline $\mathrm{COPg}$ & 3.1 & 3.1 & 3.1 & - \\
\hline Electric resistance energy factor & - & - & - & 0.9 \\
\hline Heat pump energy factor & - & - & - & 2.4 \\
\hline
\end{tabular}

\footnotetext{
a. Rated COP based on entering air temperature of $80.6^{\circ} \mathrm{F} \mathrm{DB}$ and $66.2^{\circ} \mathrm{F} \mathrm{WB}$, and entering water temperature of $77^{\circ} \mathrm{F}$. Actual average COP based on 17 to 22 months of data.

b. Rated COP based on entering air temperature of $68^{\circ} \mathrm{F} \mathrm{DB}$ and $59^{\circ} \mathrm{F} \mathrm{WB}$, and entering water temperature of 30 ${ }^{\circ} \mathrm{F}$. Actual average COP based on 14 to 24 months of data.

c. Rated at $95^{\circ} \mathrm{F}$

d. Rated at $47^{\circ} \mathrm{F}$

e. Rated at $95^{\circ} \mathrm{F}$

f. Rated at $32{ }^{\circ} \mathrm{F}$

g. Based on entering water source temperature of $32^{\circ} \mathrm{F}$ and entering water load temperature of $100{ }^{\circ} \mathrm{F}$.
} 


\section{Appendix B: Equation Derivations}

\section{Derivation of Equations 2 and 3}

Derivation of the equations to estimate indoor formaldehyde concentration. The variables used in this and the following sections are described in Section 2.4.

$V^{d C_{i n} / d t}=Q C_{\text {out }}+E-Q C_{\text {in }}-\eta Q_{f} C_{\text {in }}+R_{s}$

where $R_{s}=-K\left(C_{i n}-C_{e q}\right) A$

$R_{S}$ is the net rate of sorption that takes into account adsorption of formaldehyde on the surface of a storage or sink material ( $\left.K C_{i n} A\right)$, and desorption of formaldehyde from the surface of a storage or sink material $\left(K C_{e q} A\right)$.

Substitute Equation [b] into Equation [a]

$$
\begin{aligned}
& V^{d C_{\text {in }} /}{ }_{d t}=Q C_{\text {out }}+E-Q C_{\text {in }}-\eta Q_{f} C_{\text {in }}-K\left(C_{\text {in }}-C_{e q}\right) A \\
& d C_{\text {in }} /_{d t}=Q C_{\text {out }} /_{V}+E /_{V}-Q C_{\text {in }} /_{V}-\left(\eta Q_{f} / V\right) C_{\text {in }}-K\left(C_{\text {in }}-C_{e q}\right) A /_{V} \\
& d C_{\text {in }} /_{d t}=\lambda C_{\text {out }}+E / V-\lambda C_{\text {in }}-\left(\eta Q_{f} / V\right) C_{\text {in }}-K L\left(C_{\text {in }}-C_{\text {eq }}\right) \\
& d C_{\text {in }} /_{d t}=\lambda C_{\text {out }}+E /_{V}+K L C_{e q}-C_{\text {in }}\left(\lambda+\eta Q_{f} /_{V}+K L\right)
\end{aligned}
$$

Let

$$
\begin{aligned}
& S=\lambda C_{\text {out }}+E / V+K L C_{e q} \\
& D=\lambda+\eta Q_{f} /_{V}+K L
\end{aligned}
$$

Here, $S$ includes all the sources: outdoors, emissions from primary sources, and desorption from secondary sources; while $D$ covers the terms that cause decreases in concentration: ventilation, filtration and adsorption to secondary sources.

Substitute Equations [d1] and [d2] into Equation [c]

$$
\begin{aligned}
& d C_{\text {in }} /_{d t}=S-D C_{\text {in }} \\
& d C_{\text {in } /_{\left(S-D C_{i n}\right)}=d t}
\end{aligned}
$$


Let

$x=S-D C_{\text {in }}$

then

$d x / d C_{\text {in }}=-D$

$d C_{i n}=-d x / D$

Substitute Equations [f1] and [f2] into Equation [e2]

$1 /{ }_{D}(d x / x)=-d t$

$\int d x / x=-D \int d t$

$\ln x+x_{1}=-D t$

Per Equation [g], at $t=0$

$x_{1}=-\ln x=-\ln \left(S-D C_{i n, t=0}\right)$

Substitute Equations [f1] and [h] into Equation [g]

$\ln \left(S-D C_{\text {in }}\right)-\ln \left(S-D C_{\text {in }, t=0}\right)=-D t$

$\ln \left(\frac{S-D C_{i n}}{S-D C_{i n, t=0}}\right)=-D t$

$\frac{S-D C_{i n}}{S-D C_{i n, t=0}}=e^{-D t}$

$S-D C_{i n}=\left(S-D C_{i n, t=0}\right) e^{-D t}=S e^{-D t}-D C_{i n, t=0} e^{-D t}$

$D C_{i n}=-S e^{-D t}+D C_{i n, t=0} e^{-D t}+S=D C_{i n, t=0} e^{-D t}+S\left(1-e^{-D t}\right)$

$C_{i n}=C_{i n, t=0} e^{-D t}+\frac{S}{D}\left(1-e^{-D t}\right)$

Substitute Equations [d1] and [d2] into Equation [i]

$C_{\text {in }}(t)=C_{\text {in }, t=0}\left[e^{-\left(\lambda+\frac{\eta Q_{f}}{V}+K L\right) t}\right]+\left[\frac{\lambda C_{o u t}+E / V+K L C_{e q}}{\lambda+\frac{\eta Q_{f}}{V}+K L}\right]\left[1-e^{-\left(\lambda+\frac{\eta Q_{f}}{V}+K L\right) t}\right]$

[j] 
From Equation [e1], concentration at steady-state is:

$C_{i n, s S}=\frac{S}{D}=\frac{\lambda C_{o u t}+{ }^{E} / V_{V}+K L C_{e q}}{\lambda+\frac{\eta Q_{f}}{V}+K L}$

Therefore, Equation [j] becomes:

$C_{i n}(t)=C_{i n, t=0}\left[e^{-\left(\lambda+\frac{\eta Q_{f}}{V}+K L\right) t}\right]+C_{i n, s s}\left[1-e^{-\left(\lambda+\frac{\eta Q_{f}}{V}+K L\right) t}\right]$

\section{Derivation of Equation 4}

Derivation of the equation to estimate the amount of time need to reach $105 \%$ of the steady-state concentration $\left(C_{105 \%, s s}\right)$ during formaldehyde decay.

Start with Equation [i] from previous section

$C_{i n}=C_{i n, t=0} e^{-D t}+\frac{S}{D}\left(1-e^{-D t}\right)=C_{i n, t=0} e^{-D t}+C_{i n, s s}\left(1-e^{-D t}\right)$

$1.05 C_{i n, s s}=C_{i n, t=0} e^{-D t_{105 \%, s s}}+C_{i n, s s}\left(1-e^{-D t_{105 \%, s s}}\right)$

$1.05 C_{i n, s s}=C_{i n, t=0} e^{-D t_{105 \%, s s}}+C_{i n, s s}-C_{i n, s s} e^{-D t_{105 \%, s s}}$

$0.05 C_{i n, s s}=C_{i n, t=0} e^{-D t_{105 \%, s s}}-C_{i n, s s} e^{-D t_{105 \%, s s}}=e^{-D t_{105 \%, s s}}\left(C_{i n, t=0}-C_{i n, s s}\right)$

$e^{-D t_{105 \%, s s}}=\frac{0.05 C_{i n, s s}}{C_{i n, t=0}-C_{i n, s s}}=\frac{0.05}{\frac{C_{i n, t=0}}{C_{i n, s s}}-1}$

$D t_{105 \%, s s}=-\ln \left(\frac{0.05}{\frac{C_{i n, t=0}}{C_{i n, S S}}-1}\right)$

$t_{105 \%, S S}=\frac{-\ln \left(\frac{0.05}{\frac{C_{i n, t=0}}{C_{i n, S S}}-1}\right)}{D}$

$t_{105 \%, S S}=\frac{-\ln \left(\frac{0.05}{C_{i n, t=0} \frac{D}{S}-1}\right)}{D}=\frac{-\ln \left(\frac{0.05}{\frac{C_{i n, t=0}}{C_{i n, S S}}-1}\right)}{\lambda+\frac{\eta Q_{f}}{V}+K L}$ 


\section{Derivation of Equation 5}

Derivation of the equation to estimate the amount of time need to reach $95 \%$ of the steady-state concentration $\left(C_{95 \%, s s}\right)$ during formaldehyde buildup.

Start with Equation [i] from previous section

$C_{i n}=C_{i n, t=0} e^{-D t}+\frac{S}{D}\left(1-e^{-D t}\right)=C_{i n, t=0} e^{-D t}+C_{i n, s s}\left(1-e^{-D t}\right)$

$0.95 C_{i n, s s}=C_{i n, t=0} e^{-D t_{95 \%, s s}}+C_{i n, s s}\left(1-e^{-D t_{95 \%, s s}}\right)$

$0.95 C_{i n, s s}=C_{i n, t=0} e^{-D t_{95 \%, s s}}+C_{i n, s s}-C_{i n, s s} e^{-D t_{95 \%, s s}}$

$0.05 C_{i n, s s}=-C_{i n, t=0} e^{-D t_{95 \%, s s}}+C_{i n, s s} e^{-D t_{95 \%, s s}}=e^{-D t_{95 \%, s s}}\left(C_{i n, s s}-C_{i n, t=0}\right)$

$e^{-D t_{95 \%, s s}}=\frac{0.05 C_{i n, s s}}{C_{i n, s s}-C_{i n, t=0}}=\frac{0.05}{1-\frac{C_{i n, t=0}}{C_{i n, s s}}}$

$D t_{95 \%, S S}=-\ln \left(\frac{0.05}{1-\frac{C_{i n, t=0}}{C_{i n, S S}}}\right)$

$t_{95 \%, S S}=\frac{-\ln \left(\frac{0.05}{1-\frac{C_{i n, t=0}}{C_{i n, s s}}}\right)}{D}$

$t_{95 \%, S S}=\frac{-\ln \left(\frac{0.05}{1-C_{i n, t=0} \frac{D}{S}}\right)}{D}=\frac{-\ln \left(\frac{0.05}{1-\frac{C_{i n, t=0}}{C_{i n, S S}}}\right)}{\lambda+\frac{\eta Q_{f}}{V}+K L}$ 


\section{Appendix C: VOC and Aldehyde Concentrations}

\section{August 2011 Survey}

Air samples were collected in Houses 3 and 4 in August of 2011. Concentrations for the monitored VOCs and aldehydes are presented in Table $\mathrm{C} 1$ and Error! Reference source not found., respectively.

Table C1. VOC concentrations measured in Houses 3 and 4 during Test 1 (August 2011).

\begin{tabular}{|c|c|c|c|c|c|}
\hline \multirow{2}{*}{ Compound } & \multicolumn{2}{|c|}{ Concentration (ppb) } & \multicolumn{2}{|c|}{ Recommended Exposure Level } & \multirow{2}{*}{ Typical Sources } \\
\hline & House 3 & House 4 & $\mathrm{ppb}$ & Source & \\
\hline Propylene glycol & 5.5 & - & 100,000 & $a$ & Acrylic paints, antifreeze, disinfectants \\
\hline a-Pinene & 29.0 & 33.5 & - & - & Cleaners, fragrances, wood products \\
\hline b-Phellandrene & 6.7 & 2.0 & - & - & Cleaners, fragrances, wood products \\
\hline b-Pinene & 4.9 & 5.0 & - & - & Cleaners, fragrances, wood products \\
\hline Camphene & 2.3 & 16.2 & - & - & Cleaners, fragrances, wood products \\
\hline d-Carene & 21.9 & 31.5 & - & - & Cleaners, fragrances, wood products \\
\hline Limonene & 7.4 & 19.4 & - & - & Cleaners, fragrances, wood products \\
\hline Naphthalene & 0.4 & 0.4 & 1.8 & $b$ & Gasoline, incomplete combustion, repellent \\
\hline 4-Isopropyltoluene & - & 2.8 & - & - & Epoxy, adhesive, sealants \\
\hline 2-Pentyl furan & 2.1 & 2.3 & - & - & Flavors, fragrances \\
\hline Acetic acid & 86.5 & 80.4 & 10,000 & a & Silicone caulks, glass cleaners \\
\hline 2-Methyl Pentane & - & 0.6 & & & Gasoline, solvents \\
\hline Decane & 2.8 & 11.3 & - & - & Gasoline, solvents \\
\hline Dodecane & 0.4 & 0.4 & - & - & Gasoline, solvents \\
\hline n-Heptane & 1.7 & 8.3 & 85,000 & a & Gasoline, solvents \\
\hline n-Hexane & - & 0.3 & 50,000 & a & Gasoline, solvents \\
\hline n-Octane & - & 1.4 & 75,000 & a & Gasoline, solvents \\
\hline o,m\&p Xylenes & 0.5 & 0.7 & 100,000 & a & Gasoline, solvents \\
\hline Toluene & 3.5 & 7.4 & 100,000 & a & Gasoline, solvents \\
\hline Undecane & 0.5 & 0.3 & - & - & Gasoline, solvents \\
\hline 2,6,7-Trimethyl Decane & 0.4 & - & - & - & Cleaners containing petroleum solvents \\
\hline 2-Methyl Decane & 0.6 & - & - & - & Cleaners containing petroleum solvents \\
\hline 2-Methyl-2-Propenoic acid & 3.3 & - & - & - & Paints, varnishes, food flavoring agents \\
\hline 2-Isopropenyltouene & - & 28.5 & & & Gasoline, solvents \\
\hline n-Butane & - & 0.8 & 800,000 & a & Gasoline, natural gas, aerosol propellants \\
\hline Propanoic acid & - & 0.7 & 10,000 & a & Oil alkyd coatings, adhesives \\
\hline Decyl Aldehyde & 1.3 & 0.8 & - & - & Perfumes, flavorings \\
\hline Nonyl Aldehyde & 6.4 & 6.9 & - & - & Perfumes, flavoring agents \\
\hline Acetophenone & 0.6 & - & - & - & Perfumes, flavorings, solvents \\
\hline n-Butanol & 3.3 & - & 50,000 & a & Solvents, paints, adhesives \\
\hline 2,4-Dimethyl-3-Pentanone & 0.4 & 1.1 & - & - & Solvents \\
\hline Pentadecane & 0.9 & 1.7 & - & - & Solvents \\
\hline 1-Pentanol & 3.3 & 5.3 & - & - & Solvents \\
\hline 1-Heptanol & 2.1 & 1.7 & - & - & Solvents \\
\hline 1-Octanol & 1.5 & 1.3 & - & - & Solvents \\
\hline 2-Heptanone & 2.1 & 3.0 & 100,000 & c & Solvents, flavorings \\
\hline Tetradecane & 0.9 & - & - & - & Solvents, petroleum hydrocarbons \\
\hline 3-Heptanone & 3.2 & - & 50,000 & c & Solvents, perfumes \\
\hline Tricyclene & - & 3.8 & - & - & Wood products \\
\hline Terpinolene & & 2.9 & - & - & Wood products \\
\hline 2-Octanone & 1.5 & 2.1 & - & - & Wood products, coatings, adhesives \\
\hline 3-Furaldehyde & & 4.8 & - & - & Wood products, coatings, adhesives \\
\hline
\end{tabular}

a. Time-weighted average (TWA) concentration for up to a 10-hour workday during a 40-hour workweek specified by the National Institute for Occupational Safety and Health (NIOSH)

b. Chronic exposure level from the California Office of Environmental and Health Hazard Assessment (OEHHA). 
Table C2. Aldehyde concentrations measured in Houses 3 and 4 during Test 1 (August 2011).

\begin{tabular}{|c|c|c|c|c|c|}
\hline \multirow{2}{*}{ Compound } & \multicolumn{2}{|c|}{ Concentration (ppb) } & \multicolumn{2}{|c|}{ Recommended Exposure Level } & \multirow{2}{*}{ Typical Sources } \\
\hline & House 3 & House 4 & $\mathrm{ppb}$ & Source & \\
\hline Formaldehyde & 172 & 89 & $16,7.4$ & $a, b$ & Compressed wood, adhesives, car exhaust \\
\hline Acetaldehyde & 20 & 55 & 78 & $\mathrm{~b}$ & Paints, tobacco smoke, car exhaust \\
\hline Acrolein & $<1$ & $<1$ & 0.15 & b & Plastic, perfumes, laminate wood products \\
\hline Propionaldehyde & 4 & 5 & - & - & Paint, laminate wood products \\
\hline Crotonaldehyde & $<1$ & $<1$ & 2,000 & a & Paint, laminate wood products \\
\hline Butyraldehyde & 4 & 5 & - & - & Food products, degradation of fats and oils \\
\hline Benzaldehyde & 4 & 3 & - & - & Oil alkyd paints, coatings, adhesives \\
\hline $0, m$ \& p Tolualdehyde & $<1$ & $<1$ & - & - & Oil alkyd paints, coatings, adhesives \\
\hline Valeraldehyde & 24 & 21 & 50,000 & a & Oil alkyd paints, coatings, adhesives \\
\hline Hexaldehyde & 49 & 63 & - & - & Oil alkyd paints, coatings, adhesives \\
\hline Heptaldehyde & 6 & 7 & - & - & Oil alkyd paints, coatings, adhesives \\
\hline
\end{tabular}

a. Time-weighted average (TWA) concentration for up to a 10-hour workday during a 40-hour workweek specified by the National Institute for Occupational Safety and Health (NIOSH)

b. Chronic exposure level from the California Office of Environmental and Health Hazard Assessment (OEHHA). 


\section{November 2011 Survey}

Baseline VOC and aldehyde concentrations were monitored in Houses 1 through 4 from late November until early December 2011. Concentrations for the monitored VOCs and aldehydes are presented in Table C3 and Table C4, respectively.

Table C3. VOC concentrations measured in Houses 1, 2, 3 and 4 during Test 2 (November 2011).

\begin{tabular}{|c|c|c|c|c|c|c|c|}
\hline \multirow{2}{*}{ Compound } & \multicolumn{4}{|c|}{ Concentration (ppb) } & \multicolumn{2}{|c|}{$\begin{array}{l}\text { Recommended } \\
\text { Exposure Level }\end{array}$} & \multirow{2}{*}{ Typical Sources } \\
\hline & House 1 & House 2 & House 3 & House 4 & $\mathrm{ppb}$ & Source & \\
\hline a-Pinene & 36.5 & 42 & 27 & 27.5 & - & - & Cleaners, fragrances, wood products \\
\hline b-Phellandrene & 11.5 & 9.8 & 8.6 & 8.5 & - & - & Cleaners, fragrances, wood products \\
\hline b-Pinene & - & 3.4 & 7.6 & 5.6 & - & - & Cleaners, fragrances, wood products \\
\hline Camphene & 2.2 & 1.7 & 1.6 & 3.1 & - & - & Cleaners, fragrances, wood products \\
\hline d-Carene & 3.8 & - & 11.5 & 13.7 & - & - & Cleaners, fragrances, wood products \\
\hline Limonene & 9.2 & 6.1 & 4.7 & 6.1 & - & - & Cleaners, fragrances, wood products \\
\hline Naphthalene & 3.1 & 0.5 & - & - & 1.8 & $\mathrm{~b}$ & Gasoline, incomplete combustion, repellent \\
\hline 2-Pentyl furan & 2.1 & - & 1.1 & 1.1 & - & - & Flavors, fragrances \\
\hline Acetic acid & 178 & 69 & 100 & 18.4 & 10,000 & a & Silicone caulks, glass cleaners \\
\hline Isopropyl Benzene & 0.6 & - & - & - & & & Gasoline \\
\hline 1,2,4-Trimethylbenzene & 4.1 & 1.5 & - & - & & & Gasoline, solvents \\
\hline 1,3,5-Trimethylbenzene & 46 & - & - & - & & & Gasoline, solvents \\
\hline 1-Ethyl-4-Methyl Benzene & 9.4 & 6.6 & - & - & & & Gasoline, solvents \\
\hline 2-Methyl Pentane & 1.4 & - & - & - & & & Gasoline, solvents \\
\hline Decane & 7.0 & 10 & - & - & - & - & Gasoline, solvents \\
\hline Dodecane & 5.6 & - & 0.4 & 0.4 & - & - & Gasoline, solvents \\
\hline Ethyl Benzene & 0.9 & - & - & 0.9 & & & Gasoline, solvents \\
\hline n-Octane & - & - & - & 1.4 & 75,000 & a & Gasoline, solvents \\
\hline o,m\&p Xylenes & 2.8 & 1.7 & 2.3 & - & 100,000 & a & Gasoline, solvents \\
\hline Toluene & 6.1 & 2.7 & 2.9 & 1.9 & 100,000 & $a$ & Gasoline, solvents \\
\hline Tridecane & 5.6 & - & - & - & & & Gasoline, solvents \\
\hline Undecane & 1.9 & 1.2 & 0.6 & 1.6 & - & - & Gasoline, solvents \\
\hline n-Propanol & - & 8.1 & - & - & & & Paints, solvents, cleaners \\
\hline 2-Methyl Decane & 9.6 & - & - & - & - & - & Cleaners containing petroleum solvents \\
\hline Nonyl Aldehdyde & 7.4 & 5.1 & 3.1 & - & & & Perfumes, oxidation of $\mathrm{C}_{9}$ alcohols \\
\hline 2-Methyl-2-Propenoic acid & - & - & 0.8 & - & - & - & Paints, varnishes, food flavoring agents \\
\hline n-Butane & - & - & - & 0.8 & 800,000 & a & Gasoline, natural gas, aerosol propellants \\
\hline Acetophenone & - & 1.0 & 0.4 & - & - & - & Perfumes, flavorings, solvents \\
\hline Acetone & 4.6 & - & 3.8 & - & & & Cleaners, adhesives, polish removers \\
\hline Styrene & 9.9 & 2.9 & - & - & & & Styrene, resins, coatings \\
\hline Isobutyl alcohol & 0.7 & 8.8 & 0.7 & & & & Solvents, cleaners, paints, adhesives \\
\hline n-Butanol & 1.0 & - & 22.1 & - & 50,000 & a & Solvents, paints, adhesives \\
\hline 1-Heptanol & 0.8 & 4.7 & 0.4 & - & - & - & Solvents \\
\hline 1-Octanol & 0.9 & - & - & - & - & - & Solvents \\
\hline 1-Pentanol & 7.8 & - & - & 2.2 & - & - & Solvents \\
\hline 2,6 Dimethyl Undecane & 8.1 & - & - & - & & & Solvents \\
\hline 2-Pentanone & 0.9 & - & 0.6 & - & & & Solvents \\
\hline 2-Heptanone & 2.1 & 3.7 & 1.9 & 0.4 & 100,000 & a & Solvents, flavorings \\
\hline Tetradecane & 0.4 & - & 0.6 & - & - & - & Solvents, petroleum hydrocarbons \\
\hline 3-Heptanone & - & - & - & 2.6 & 50,000 & a & Solvents, perfumes \\
\hline 2-Octanone & - & - & - & 1.0 & - & - & Wood products, coatings, adhesives \\
\hline Furfuraldehyde & - & 2.5 & - & 0.5 & & & Week killers, fungicides \\
\hline
\end{tabular}

a. Time-weighted average (TWA) concentration for up to a 10-hour workday during a 40-hour workweek specified by the National Institute for Occupational Safety and Health (NIOSH)

b. Chronic exposure level from the California Office of Environmental and Health Hazard Assessment (OEHHA). 
Table C4. Aldehyde concentrations in Houses 1 through $4^{a}$ measured during Test 2 (November 2011).

\begin{tabular}{|c|c|c|c|c|c|c|c|}
\hline \multirow{3}{*}{ Compound } & \multicolumn{4}{|c|}{ Concentration (ppb) } & \multicolumn{2}{|c|}{$\begin{array}{l}\text { Recommended } \\
\text { Exposure Level }\end{array}$} & \multirow{3}{*}{ Typical Sources } \\
\hline & House & House & House & House & & Sourc & \\
\hline & 1 & 2 & 3 & 4 & $\mathrm{ppb}$ & $\mathrm{e}$ & \\
\hline Formaldehyde & 22 & 49 & 113 & 54 & $16,7.4$ & $a, b$ & Compressed wood, adhesives, car exhaust \\
\hline Acetaldehyde & 5 & 22 & 13 & 44 & 78 & $b$ & Paints, tobacco smoke, car exhaust \\
\hline Acrolein & $<1$ & $<1$ & $<1$ & $<1$ & 0.15 & $b$ & Plastic, perfumes, laminate wood products \\
\hline Propionaldehyde & 5 & 4 & 3 & 4 & - & - & Paint, laminate wood products \\
\hline Crotonaldehyde & 1 & $<1$ & $<1$ & $<1$ & 2,000 & a & Paint, laminate wood products \\
\hline Butyraldehyde & 2 & 3 & 1 & 2 & - & - & Food products, degradation of fats and oils \\
\hline Benzaldehyde & 2 & 2 & 2 & 2 & - & - & Oil alkyd paints, coatings, adhesives \\
\hline o,m\&p Tolualdehyde & 1 & $<1$ & $<1$ & 4 & - & - & Oil alkyd paints, coatings, adhesives \\
\hline Valeraldehyde & 3 & 12 & 9 & 12 & 50,000 & a & Oil alkyd paints, coatings, adhesives \\
\hline Hexaldehyde & 11 & 42 & 17 & 39 & - & - & Oil alkyd paints, coatings, adhesives \\
\hline Heptaldehyde & 12 & $<1$ & 3 & 3 & - & - & Oil alkyd paints, coatings, adhesives \\
\hline
\end{tabular}

a. Time-weighted average (TWA) concentration for up to a 10-hour workday during a 40-hour workweek specified by the National Institute for Occupational Safety and Health (NIOSH)

b. Chronic exposure level from the California Office of Environmental and Health Hazard Assessment (OEHHA). 